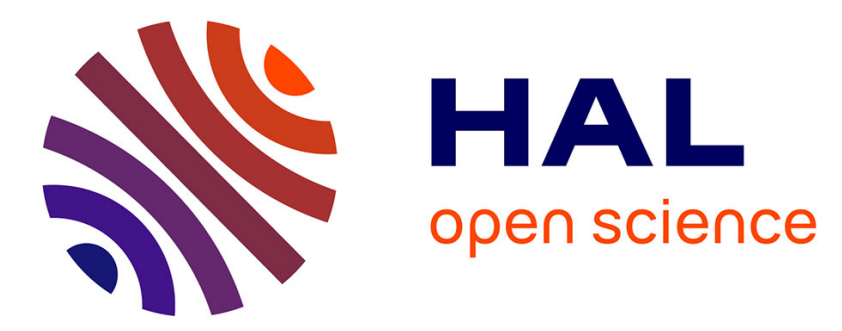

\title{
Development of conducting polychloroprene rubber using imidazolium based ionic liquid modified multi-walled carbon nanotubes
}

\author{
Kalaivani Subramaniam, Amit Das, Gert Heinrich
}

\section{- To cite this version:}

Kalaivani Subramaniam, Amit Das, Gert Heinrich. Development of conducting polychloroprene rubber using imidazolium based ionic liquid modified multi-walled carbon nanotubes. Composites Science and Technology, 2011, 71 (11), pp.1441. 10.1016/j.compscitech.2011.05.018 . hal-00773222

\section{HAL Id: hal-00773222 \\ https://hal.science/hal-00773222}

Submitted on 12 Jan 2013

HAL is a multi-disciplinary open access archive for the deposit and dissemination of scientific research documents, whether they are published or not. The documents may come from teaching and research institutions in France or abroad, or from public or private research centers.
L'archive ouverte pluridisciplinaire HAL, est destinée au dépôt et à la diffusion de documents scientifiques de niveau recherche, publiés ou non, émanant des établissements d'enseignement et de recherche français ou étrangers, des laboratoires publics ou privés. 


\section{Accepted Manuscript}

Development of conducting polychloroprene rubber using imidazolium based ionic liquid modified multi-walled carbon nanotubes

Kalaivani Subramaniam, Amit Das, Gert Heinrich

PII:

S0266-3538(11)00192-8

DOI:

10.1016/j.compscitech.2011.05.018

Reference:

CSTE 4998

To appear in:

Composites Science and Technology

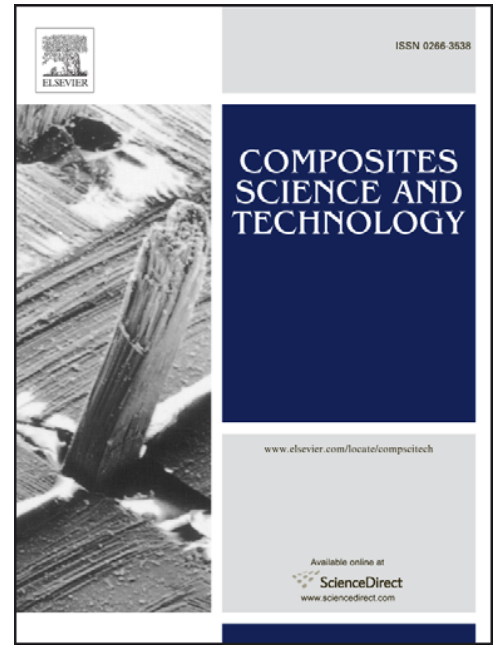

Received Date: $\quad 17$ December 2010

Revised Date: $\quad 18$ May 2011

Accepted Date: $\quad 28$ May 2011

Please cite this article as: Subramaniam, K., Das, A., Heinrich, G., Development of conducting polychloroprene rubber using imidazolium based ionic liquid modified multi-walled carbon nanotubes, Composites Science and Technology (2011), doi: 10.1016/j.compscitech.2011.05.018

This is a PDF file of an unedited manuscript that has been accepted for publication. As a service to our customers we are providing this early version of the manuscript. The manuscript will undergo copyediting, typesetting, and review of the resulting proof before it is published in its final form. Please note that during the production process errors may be discovered which could affect the content, and all legal disclaimers that apply to the journal pertain. 


\title{
Development of conducting polychloroprene rubber using imidazolium based ionic liquid modified multi- walled carbon nanotubes
}

\author{
Kalaivani Subramaniam ${ }^{\text {a }}$, Amit Das ${ }^{\text {a }}$, Gert Heinrich ${ }^{\text {a,b,* }}$
}

${ }^{a}$ Leibniz-Institut für Polymerforschung Dresden e.V. , Hohe Str. 6, 01069, Dresden, Germany

b Technische Universität Dresden, Institut für Werkstoffwissenschaft, Helmholtzstrasse 7, 01069 Dresden, Germany

*Corresponding author: Tel.: +49 3514658 360; Fax: +49 3514658362

E-mail address: gheinrich@ipfdd.de (G.Heinrich)

\begin{abstract}
A simplified and an eco-friendly approach to develop polychloroprene rubber composites with high electrical conductivity is reported. The usage of room temperature ionic liquid, 1-butyl 3-methyl imidazolium bis(trifluoromethylsulphonyl)imide and a low concentration $(5 \mathrm{phr}$ ) of commercial grade multi-walled carbon nanotubes (MWCNTs) in polychloroprene rubber exhibited an electrical conductivity of $0.1 \mathrm{~S} / \mathrm{cm}$ with a stretchability $>500 \%$. The physical (cation-pi/pi-pi) interaction between the ionic liquid and the MWCNTs is evidenced by Raman spectroscopy. Transmission electron microscopy images exhibit an improved dispersion of the BMI modified tubes in matrix at various magnification scales. The dependency of dynamic properties on the concentration of ionic liquid at constant loading of nanotubes supports the fact that ionic liquid assists in the formation of filler-filler networks. The tensile modulus of $3 \mathrm{phr}$ loaded modified MWCNT/CR composite is increased by 50\% with regard to that of the unmodified MWCNT/CR composite. Mooney-Rivlin plot displays the existence of rubber-filler interactions.
\end{abstract}


Keywords: A. Carbon nanotubes, A. Nano composites, B. Electrical properties, B. Mechanical properties, Ionic liquids

\section{Introduction}

Multi-walled carbon nanotubes (MWCNTs) can be envisaged as number of cylindrical shells made of graphitic sheets with fullerene-like end-caps [1]. With diameter ranging from 1-100 nm, length up to few millimeter, density range between 1 and $2 \mathrm{~g} / \mathrm{cm}^{3}$ and Young's modulus greater than $1 \mathrm{TPa}$ [2,3], this unique material creates plethora of opportunities in the field of science and technology. However, the biggest challenge is to disperse the individual tubes as they tend to form agglomerates or bundles due to the van der Waals interaction between them. Furthermore, processing of the tubes is also rendered difficult due to their poor solubility in aqueous and nonaqueous solvents [4]. In spite of its complications, carbon nanotubes (CNTs) have been extensively studied as reinforcing and electrically conducting filler in most of the thermoplastic and thermosetting matrices such as high density polyethylene, polycarbonate, polyamide, polystyrene, thermoplastic polyurethane and epoxy [5-7].

But all the studies were based on the usage of unmodified CNTs in thermoplastic matrices. The effect of CNTs has been dealt with a limited number of elastomers, although a variety of applications could be visualised using such composites.

Considering the case of rubber matrices, dry and wet mixing of the tubes [8-11] have been considered so far. The latter necessitates an additional step of ultrasonification for dispersion of CNTs in organic solvents and moreover, the employment of such solvents is detrimental to the environment. A review article on multiwalled carbon nanotube elastomeric composites shows a precise overview of the work attempted so far and deals 
with the difficulties in obtaining a homogeneous dispersion of the tubes in matrices [8].

Das et al. described a new route to disperse MWCNTs in elastomeric system and they found that the premixing of MWCNTs in ethanol improved the dispersion of the tubes in solution styrene butadiene/butadiene rubber and suggested that the wet mixing using ethanol is better than the conventional dry mixing of the tubes [9]. With the same technique, MWCNTs filled rubber composites with superior mechanical performance was developed. With the addition of just 1.6 vol\% of CNTs to different elastomer systems, significantly steeper stress-strain curves were obtained. Particularly in natural rubber system, the fatigue crack propagation resistance, tensile properties and electrical conductivity were remarkably improved in the presence of MWCNTs [10]. Endo et. al prepared MWCNTs-reinforced fluoro-elastomer for high pressure and high temperature sealing application [12]. All the above discussed studies were based on unmodified CNTs and not with ionic liquid modified CNTs.

Covalent functionalisations $[13,14]$ have been attempted to improve the interfacial properties of the tubes. Even though the chemical functionalisation impairs the pi electronic conjugation of the tubes, the rubber-filler interaction is said to be improved at the cost of electrical conductivity. A prodigious amount of work has been carried out with the functionalised tubes in various matrices $[15,16]$.

Ionic liquids (ILs) are organic salts, widely promoted as "Designer Solvents" because the properties can be tailored based on the choice of cations and anions and as "Green Solvents" because of their low vapour pressure [17]. They are non-flammable, thermally and chemically stable and found to be a promising replacement for traditional organic solvents. Fukushima et.al have found that imidazolium based room temperature ionic liquids can be employed to disperse single walled carbon nanotubes (SWCNTs) 
by means of cation-pi/pi-pi interaction [18]. It has been mentioned that the highly entangled SWCNTs bundles are exfoliated to give much finer bundles which aids in better dispersion. This new approach with ionic liquids offers possibilities for various applications of elastomer, e.g. a rubber-like stretchable active matrix using elastic conductors [19]. In this work, vinylidene fluoride-hexafluoropropylene copolymerSWCNTs composite coated with PDMS (poly-dimethyl-siloxane rubber) was prepared and the elongation at break was found to be $134 \%$. The material has limited applicability due to the low mechanical performance. It has been reported that the coupling activity of functional ionic liquid between MWCNTs and diene elastomer shows improvement in the tensile strength and the electrical conductivity [11]. Although the studies based on wet mixing and covalent functionalisation of the tubes manifest new strategies to ease the dispersion of the tubes, the full exploitation of the extra-ordinary reinforcement of elastomers using MWCNTs is still a question, and a new area of research is expected. In order to get high conducting elastic materials with the incorporation of carbon nanotubes, the dispersion and the CNTs network play a vital role. To the best of our knowledge, there is still no report about the development of elastic materials with high electrical conductivity and stretch ability using ionic liquid modified MWCNTs. In the present study, on the basis of the findings discussed earlier, an elastomeric conductor is developed employing IL modified MWCNTs and polychloroprene rubber (CR). The modification of MWCNTs was accomplished with imidazolium based room temperature IL and the resultant black mix obtained after modification was directly admixed into CR without the necessity of an organic solvent. This eco-friendly method, apart from the reduction in mixing cycle, improves the electrical conductivity and the dispersion of the tubes in CR which were confirmed by 
conductivity and TEM measurements respectively. Furthermore, the influence of varied proportions of IL on the elastomer was also studied. This relatively new field of research provides a lot of opportunities to combine the characteristics of electroconductive MWCNTs and ion conductive IL in a non conducting/conducting polymer matrix and several new applications in the field of electrochemistry such as batteries, capacitors, actuators and sensors can be developed [20,21]. The CR is chosen considering the polarity factor of the elastomer and IL respectively. Moreover, the effect of MWCNTs on CR is not dealt so far. In the current paper, the efficacy of ionic liquid modified MWCNTs on CR is discussed.

\section{Experimental}

\subsection{Materials}

The commercial multiwalled carbon nanotubes were procured from Nanocyl S.A. (Nanocyl 7000), Sambreville, Belgium. The diameter of the tubes ranges from 10 to 20 $\mathrm{nm}$ and the average length is $1.5 \mu \mathrm{m}$. The carbon content of the material is $90 \%$ and the rest is metal oxide (impurity). The polychloroprene rubber (Baypren 611, Mooney viscosity $\mathrm{ML}(1+4)$ at $\left.100^{\circ} \mathrm{C}: 43 \pm 6\right)$ and ionic liquid, 1-butyl 3-methyl imidazolium bis (trifluoromethylsulphonyl) imide (BMI) were obtained from Lanxess, Germany and Sigma-Aldrich, Steinheim, Germany respectively. Table 1 provides the chemical structure of the above materials. The zinc oxide $(\mathrm{ZnO})$, magnesium oxide $(\mathrm{MgO})$, stearic acid and ethylene thiourea (ETU) used in this study were of industrial grades. 


\subsection{Preparation of composites}

The MWCNTs were modified with BMI by grinding them in different ratios by weight of CNTs to BMI, till a black paste was obtained. The modification was done in the following ratios, 1:1, 1:5, 1:10 and 1:20 respectively. The amount of the tubes used in the study is $0.5,1,2,3,5$ and 10 parts per hundred rubber (phr). The modified MWCNTs were mixed with CR in a laboratory scale two roll mixing mill (Polymix 110L, size: 203 X $102 \mathrm{~mm}$, Servitech GmbH, Wustermark, Germany) at $40^{\circ} \mathrm{C}$ with a friction ratio of 1:1.25. The curing package (in phr) of CR consist of $\mathrm{ZnO}-5, \mathrm{MgO}-4$, stearic acid - 0.5 and ethylene thiourea - 1 and was incorporated into the matrix after the admixing of MWCNTs. The process is illustrated in Figure 1. Samples were prepared in four categories. Category 1: CR with curatives; category 2: CR with BMI (5, 10 and 20 phr); category 3: CR with unmodified tubes; category 4: CR with BMI modified tubes. The optimum cure time $\left(\mathrm{t}_{90}\right)$ was determined in a moving die rheometer, shortly referred as MDR (Scarabaeus V50, Scarabaeus GmbH, Langgöns, Germany) at $160^{\circ} \mathrm{C}$ for 60 minutes. The definition of the terms associated with the vulcanisation is as follows: The difference between the maximum $\left(\mathrm{M}_{\mathrm{H}}\right)$ and the minimum torque $\left(\mathrm{M}_{\mathrm{L}}\right)$ of the vulcanisation curve is defined as the ultimate rheometric torque $\left(\mathrm{M}_{\mathrm{H}}-\mathrm{M}_{\mathrm{L}}\right)$. The time required to reach $90 \%$ of $\left(\mathrm{M}_{\mathrm{H}}-\mathrm{M}_{\mathrm{L}}\right)$ is termed as $\mathrm{t}_{90}$. The mixed stocks were cured in a standard hot press at $160^{\circ} \mathrm{C}, 150 \mathrm{kN}$ pressure and at an optimum cure time $\left(\mathrm{t}_{90}\right)$ of the samples. The samples were designated as $\mathrm{CT}_{\mathrm{m}} \mathrm{BMI}_{\mathrm{n}}$ where $\mathrm{C}, \mathrm{T}$ and $\mathrm{BMI}$ are referred to $\mathrm{CR}$, tubes and BMI respectively. The alphabet $\mathrm{m}$ and $\mathrm{n}$ indicates the amount of the tubes and $\mathrm{BMI}$ respectively. For instance, $\mathrm{CT}_{0}$ is assigned to neat $\mathrm{CR}$ without tubes; $\mathrm{CT}_{1} \mathrm{BMI}_{1}$ is assigned to $\mathrm{CR}$ composite consisting of $1 \mathrm{phr}$ of tubes admixed with BMI in the ratio $1: 1 ; \mathrm{CT}_{3} \mathrm{BMI}_{20}$ is assigned to $\mathrm{CR}$ composite consisting of $3 \mathrm{phr}$ of tubes 
admixed with $\mathrm{BMI}$ in the ratio $1: 20 ; \mathrm{CT}_{0} \mathrm{BMI}_{10}$ is assigned to $\mathrm{CR}$ containing $10 \mathrm{phr}$ of BMI and so on.

\subsection{Characterisation}

The Raman spectroscopy was performed with a Raman spectrometer Holoprobe 785 (Kaiser Optical Systems), which is equipped with a $400 \mathrm{~mW}$ diode laser with an excitation wavelength of $785 \mathrm{~nm}$. Transmission Electron Microscopy images were obtained on a Libra 120 transmission electron microscope at an acceleration voltage of $120 \mathrm{kV}$. Samples were sectioned by ultramicrotomy at a temperature of $-140{ }^{\circ} \mathrm{C}$. Electrical volume resistivity measurements were determined at room temperature depending on the sample resistivity. A Keithley Electrometer 6517A was employed with 8009 resistivity fixture (resistivity $>10^{7} \Omega \mathrm{cm}$ ) and four point text fixture (low resistivity) respectively. Dynamic Mechanical Thermal Analysis (DMTA) was performed on Eplexor 150 N (Gabo Qualimeter, Ahlden, Germany) in the tension mode, at a constant frequency of $10 \mathrm{~Hz}$, static load at $1 \%$ strain, dynamic load at $0.5 \%$ strain, heating rate of $2 \mathrm{~K} / \mathrm{min}$ under nitrogen flow and the temperature range from -100 to 100 ${ }^{\circ}$ C. Strain sweep measurement was performed on Eplexor 2000 N (Gabo Qualimeter, Ahlden, Germany) in the tension mode at room temperature, at a constant frequency of $10 \mathrm{~Hz}$, static load at $60 \%$ strain and dynamic load, 0.01 to $30 \%$. Tensile testing was done on a Universal Testing Machine, UTM (Zwick 1456, Z010, Ulm, Germany) with a crosshead speed of $500 \mathrm{~mm} / \mathrm{min}$ using dumb-bell shaped specimens.

\section{Results and discussion}

\subsection{Characterisation of BMI modified MWCNTs}


The Raman spectrum of the pristine and the modified MWCNTs is shown in Figure 2. Similar to graphite, two strong peaks are observed. The peak around $1600 \mathrm{~cm}^{-1}$ originates from the tangential vibrations of the carbon atoms and is referred as $\mathrm{G}$ band. The band around $1300 \mathrm{~cm}^{-1}$ is assigned as $\mathrm{D}$ band and it may be caused by the significant defects or disorders in the nanostructures [22]. The radial breathing mode (RBM) of the tubes, which normally observed at $100-200 \mathrm{~cm}^{-1}$, could not be clearly observed as in Single Walled Carbon Nanotubes (SWCNTs). Since MWCNTs contain an ensemble of the tubes ranging from lower to higher diameter, the RBM signal from the large diameter tubes is usually too weak to observe [23]. For the modified tubes, there exists a slight shift of $3-4 \mathrm{~cm}^{-1}$ for both $\mathrm{D}$ and $\mathrm{G}$ bands and no new vibrations are observed in opposition to the pristine MWCNTs. It has also been reported that no shifts in D and G lines were observed in SWCNTs modified with ILs $[24,25]$. The up shift in the spectra is probably due to the cation- $\pi$ interaction between BMI and the tubes and/or the perturbation of $\pi-\pi$ stacking of multi-walls of the tubes. To conclude, it can be stated that the modification is activated physically, without chemical impairment of MWCNTs, in accordance with the earlier results [24,25].

\subsection{Electrical conductivity}

Carbon nanotubes can be considered as wires in which the electrons can propagate

freely. The insulating rubber matrix becomes conducting after a critical concentration of the tubes, called the percolation threshold $\left(\phi_{\mathrm{c}}\right)$ wherein a continuous network of filler is formed across the matrix. CNTs have low $\phi_{\mathrm{c}}$ because of the high aspect ratio of the nanotube bundles which improves the probability of particle-particle contact. Low $\phi_{\mathrm{c}}$ of single walled carbon nanotubes in polymer hosts ranges from 0.005 vol\% to several 
vol\% [5]. However, such low $\phi_{\mathrm{c}}$ was not reported in any of the rubber matrices. The percolation threshold and conductivity depend strongly on the type of the polymer, aspect ratio of CNTs, disentanglement of CNT agglomerates, distribution of individual CNTs and degree of alignment [26]. Figure 3a illustrates the electrical conductivity of gum CR and the composites with BMI modified tubes. The electrical conductivity of pristine rubber is found to be $4.69 \times 10^{-11} \mathrm{~S} / \mathrm{cm}$. As known, the increase in the amount of MWCNTs results in a proportional increase in the conductivity. Two different ratios of MWCNTs to BMI $(1: 1,1: 20)$ were compared as shown in the figure. The plot shows that higher the ratio of MWCNTs to BMI, higher the conductivity. It is worthy to note the conductivity of $\mathrm{CT}_{3} \mathrm{BMI}_{20}$ which is in the range of $10^{-2} \mathrm{~S} / \mathrm{cm}$ and it is $\sim 10^{5}$ times higher than the value reported at the same concentration of the tubes in the literature $[9,27]$. Nevertheless, the mixing strategy and the employed system were different and moreover, the studies were based on either using unmodified or covalently modified CNTs.

As BMI has an inherent property of ionic conductivity, the contribution of ions to the conductivity of the composite should also be discussed. Figure $3 \mathrm{~b}$ and $3 \mathrm{c}$ show the influence of BMI on the ionic and electrical conductivity of the composites respectively. The ionic conductivity of the CR/BMI mixture increases from $10^{-11} \mathrm{~S} / \mathrm{cm}$ (neat $\mathrm{CR}$ ) to $10^{-9} \mathrm{~S} / \mathrm{cm}(5 \mathrm{phr}$ ) and remains unchanged upon loading till $20 \mathrm{phr}$ of BMI (Figure 3b). Similarly, the electrical conductivity of the composite at constant loading of the tubes with variations in BMI (ratio) also shows a drastic increment initially and a marginal difference is noted later on (Figure 3c). From the figures, the following conclusions are made. (a) The conductivity of the composite is the synergistic effect of electrons and ions (b) By increasing the amount of BMI, a proportional increase in 
conductivity is not observed (c) The improved dispersion (as seen from TEM images discussed later) and the formation of percolating CNTs network with the BMI modified tubes also leads to increased conductivity (d) Even though the amplitude sweep measurement (discussed later) illustrates the strengthening of filler-filler network upon increasing BMI, a corresponding increment in conductivity is not observed.

\subsection{TEM measurement}

The TEM images of CR composites are shown in Figure 4. In case of $\mathrm{CT}_{3} \mathrm{BMI}_{0}$ (Figure $4 \mathrm{a}$ and $4 \mathrm{~b}$ ), the state of dispersion of CNTs is poor. $\mathrm{CT}_{3} \mathrm{BMI}_{1}$ depicts the existence of agglomerates in the system (Figure $4 \mathrm{c}$ and $4 \mathrm{~d}$ ) where as $\mathrm{CT}_{3} \mathrm{BMI}_{5}$ and $\mathrm{CT}_{3} \mathrm{BMI}_{10}$ show fine dispersion of the tubes with few agglomerates as the presence of agglomerates become inevitable at concentrations $\geq 3 \mathrm{phr}$ (Figure $4 \mathrm{e}-\mathrm{h}$ ). The former can be attributed to the insufficient amount of BMI to disperse the tubes in the matrix and the efficacy of the excess BMI is clearly observed in the latter. The exfoliation of the bundles of entangled MWCNTs in the presence of BMI leads to a better dispersion of the tubes. In order to ensure improved dispersion and distribution of the tubes in the composites, sufficient quantity of BMI is required. At a lower magnification scale $(1000 \mathrm{~nm})$, it is seen that the dispersion of the tubes in the matrix is enhanced with an increasing proportion of BMI. The presence of tube-tube contact and improved dispersion in the case of modified MWCNT/CR composites is the reason behind good electrical conductivity. 


\subsection{Amplitude sweep}

The strain amplitude dependence of $\mathrm{E}^{\prime}$ for $\mathrm{CR}$ and the composites is illustrated in Figure 5. The filled elastomers are generally considered as 'non-linear viscoelastic materials' due to the fact that their dynamic mechanical properties depends on dynamic strain amplitude in addition to temperature and frequency [28]. The storage modulus, E' decreases from $\mathrm{E}_{0}^{\prime}$ (zero-amplitude plateau) to $\mathrm{E}_{\infty}^{\prime}$ (high-amplitude plateau) and the non-linear behaviour is attributed to the breakdown of the secondary aggregate network of fillers and termed as Payne effect [29]. $\mathrm{CT}_{0}$ almost shows a straight line in the figure (Figure 5a). It is important to note that even at $1 \mathrm{phr}$ loading of MWCNTs, Payne effect is observed in the composite. This could be associated with the network formation of exfoliated MWCNTs in the rubber matrix, which is broken down with the increase in the strain amplitude. The observation of Payne effect at low loading of MWCNTs can be possible only by its fine dispersion with the use of BMI. The Payne effect exhibited by $\mathrm{CT}_{10} \mathrm{BMI}_{1}$ is tremendous, wherein $\mathrm{E}_{0}^{\prime}$ increases from $\sim 3 \mathrm{MPa}$ to $\sim 63 \mathrm{MPa}$, which is exceptionally high and is basically attributed to the decrease in the distance between the tubes at high loading (10 phr) and the filler-filler networks increases [30]. It is interesting to perceive the influence of BMI on E' upon increasing the strain amplitude and the proportion of BMI (Figure 5b). An increase and a decrease in Payne effect is reported with a better dispersion of the CNTs and silica fillers in matrices respectively $[30,31]$. In our study, at a constant loading ( $3 \mathrm{phr})$ of fillers, $\mathrm{E}^{\prime}$ is found to increase just by varying the proportion of BMI. It is amazing to note the rise in $\mathrm{E}_{0}^{\prime}$ from $\sim 7 \mathrm{MPa}$ $\left(\mathrm{CT}_{3} \mathrm{BMI}_{0}\right)$ to $\sim 13 \mathrm{MPa}\left(\mathrm{CT}_{3} \mathrm{BMI}_{20}\right)$, which emphasises the significance of $\mathrm{BMI}$ that aids in the dispersion of the tubes and thereby strengthening the filler network. In the present case, from the TEM images of BMI modified MWCNT/CR composites (Figure 
4), the presence of agglomerates is found to be minimum and the dispersion of the tubes is well-marked. Hence, it is believed that the bundles of MWCNTs is disturbed due to the reduction in the inter-tubular attraction between CNTs in presence of BMI and filler-filler networks are found to be improved with well dispersed MWCNTs by increasing the proportion of BMI. A scheme shown in Figure 5c illustrates the formation of MWCNT networks in presence of BMI.

\subsection{Dynamic mechanical thermal analysis}

The storage modulus (E'), loss modulus (E") and loss tangent (tan $\delta$ ) as a function of temperature for CR composites are illustrated in Figure 6. At the glass transition temperature $\left(\mathrm{T}_{\mathrm{g}}\right)$, the molecular chains obtain sufficient energy (from thermal sources) to surmount the energy barriers for bond rotation. In this changeover regime, the fall in $E^{\prime}$ is typically few orders of magnitude and large peaks occur in the values of E" and loss tangent, $\tan \delta\left(\mathrm{E}^{\prime \prime} / \mathrm{E}^{\prime}\right)$. From the figure (Figure 6a) it is apprehended that, $\mathrm{CT}_{3} \mathrm{BMI}_{0}$ shows an increase in $\mathrm{E}^{\prime}$ in the plateau region in opposition to $\mathrm{CT}_{0}$, which can be attributed to the hydrodynamic reinforcement, filler-filler and the rubber-filler interactions. From the loss tangent curves (Figure 6b), it is noticed that the peak height of $\tan \delta$ decreases for $\mathrm{CT}_{3} \mathrm{BMI}_{0}$ with regard to $\mathrm{CT}_{0}$, which can be ascribed to the rise in $\mathrm{E}^{\prime}$ of the composites described above, as $\tan \delta$ is a ratio of $\mathrm{E}^{\prime \prime}$ to $\mathrm{E}^{\prime}$ and to the reduction in the quantity of bulk rubber as a result of interaction of rubber chains with MWCNTs. Moreover, the value of plateau modulus increases for $\mathrm{CT}_{3} \mathrm{BMI}_{5}$ and decreases for $\mathrm{CT}_{3} \mathrm{BMI}_{20}$. Though the excess BMI enhanced the dispersion of the tubes, its surplus presence affects the storage modulus of the composite, as it acts as a plasticizer. This 
argument is in agreement with the tensile modulus data (from stress-strain measurements) discussed later.

The $\mathrm{T}_{\mathrm{g}}$ of the elastomer is often taken to be the temperature of the maximum loss modulus $\left(\mathrm{E}^{\prime \prime} \max \right)$ or the maximum loss tangent $\left(\tan \delta_{\max }\right)$. However, there are several arguments in favor of defining $T_{g}$ in terms of $E^{\prime \prime}{ }_{\max }$ instead of $\tan \delta_{\max }[32,33]$. It has been affirmed that $\mathrm{T}_{\mathrm{g}}$ by $\mathrm{E}$ " becomes a more consistent and an appropriate index than $\tan \delta$. The $\mathrm{T}_{\mathrm{g}}$ based on $\mathrm{E}^{\prime \prime}\left(-33^{\circ} \mathrm{C}\right)$ and $\tan \delta\left(-25^{\circ} \mathrm{C}\right)$ almost remains the same for neat elastomer and the composites. Most of the investigations report an increase or decrease in $\mathrm{T}_{\mathrm{g}}$ and in some cases no change in $\mathrm{T}_{\mathrm{g}}$ upon adding conventional and nano-sized fillers in elastomers $[8,9,34]$. Nevertheless, it depends on the interfacial interactions between filler and elastomer. It is also important to note that the peak in $\tan \delta$ occurs $8{ }^{\circ} \mathrm{C}$ higher than the peak in E", which confirms the behaviour mentioned elsewhere [32]. A secondary shoulder seen in $\mathrm{E}^{\prime \prime}$ curve of $\mathrm{CT}_{3} \mathrm{BMI}_{5}\left(-76^{\circ} \mathrm{C}\right)$ and $\mathrm{CT}_{3} \mathrm{BMI}_{20}\left(-79{ }^{\circ} \mathrm{C}\right)$ is attributed to the relaxation process associated with IL. Probably, this could be related to free ILs that are not associated with CNTs. Ionic liquid, which exhibits disordered and fragile structure, can also form glassy-like state and could be traced by calorimetric measurements [35]. Here, it is found that, with the increase in the proportion of ionic liquid, the glass transition temperature of the ionic liquid decreases.

\subsection{Mechanical characterisation}

Figure 7a illustrates the stress strain curves of neat CR and the composites. A typical non-linear curve is noticed. At a given strain, a significant increment in stress is observed with an increase in the amount of MWCNTs. Even the samples with high loading of MWCNTs (5 and $10 \mathrm{phr}$ ) exhibited a strechability of $>500 \%$. The influence 
of BMI on the tensile modulus of the unmodified and modified MWCNT composites at $300 \%$ elongation is shown in Figure $7 \mathrm{~b}$. It is seen that, the increment in tensile modulus is proportional to the increment in the amount of BMI at a constant loading of fillers (3 phr). Tensile modulus of $3 \mathrm{phr}$ loaded modified MWCNT/CR composite is increased by $50 \%$ with regard to unmodified MWCNT/CR composite. However, for $\mathrm{CT}_{3} \mathrm{BMI}_{20}$, tensile modulus decreases. It is correlated to the fact that the excess BMI employment can act as plasticizers as discussed earlier and affects the physical properties. Although there is an improvement in the dispersion of the tubes with an increase in the proportion of BMI, there is no corresponding improvement in the mechanical properties of the composite. Therefore, an optimal amount of BMI can be chosen based on the requirements.

The Mooney-Rivlin equation [36,37] describes the stress strain behaviour of unfilled elastomers:

$$
\sigma_{r e d}=\frac{\sigma}{\left(\lambda-\frac{1}{\lambda^{2}}\right)}=2 C_{1}+\frac{2 C_{2}}{\lambda}
$$

$\sigma$ is the tensile stress (force divided by undeformed cross sectional area), $\lambda$ is the extension ratio (ratio of the final length in the direction of stretch $(\mathrm{L})$ to the initial length before deformation $\left.\left(\mathrm{L}_{0}\right)\right)$ and $\mathrm{C}_{1}$ and $\mathrm{C}_{2}$ parameters characteristic of the rubber vulcanisate. The value of $\mathrm{C}_{1}$ is directly proportional to the elastically active network chains per unit volume of the rubber and $\mathrm{C}_{2}$ is related to the number of elastically effective trapped entanglements, number of steric obstructions and other network defects. In the case of filled systems, the matrix is prevented from deforming uniformly by adhesion of the rubber to the surface of the filler. So, the overall apparent strain is less than the strain occurring locally [38]. For filled systems, a strain amplification 
factor $\mathrm{X}$ is considered which takes into account both the disturbance of strain distribution and the absence of deformation of fillers. The factor is derived from Guth equation [39].

$$
\mathrm{X}=1+2.5 c+14.1 c^{2}
$$

$c$ is the filler volume concentration.

The modified extension ratio $\lambda^{*}$ of filled rubbers is calculated from the following equation.

$$
\lambda *=1+\mathrm{X} e
$$

$e$ is the ratio of the extension length $(\Delta \mathrm{L})$ to the initial length $\left(\mathrm{L}_{0}\right)$. From Figure $7 \mathrm{c}$, it is seen that the curves display upturn in the stress at higher deformation. $\mathrm{CT}_{0}$ shows an abrupt increase in the reduced stress at higher deformation which can be correlated to the strain induced crystallisation of CR. It is worthy to note that the upturn at higher deformation occurs at lower strain for $\mathrm{CT}_{3} \mathrm{BMI}_{1}$, which indicates an existence of interaction between the MWCNTs and CR and the type of interaction is not identified so far.

\section{Conclusion}

A feasible and easy method for the preparation of highly electro-conducting and truly elastic materials at a low concentration of commercially available MWCNTs is developed. CR based elastic conductor using ionic liquid modified MWCNTs with conductivity as high as $\sim 0.1 \mathrm{~S} / \mathrm{cm}$ and a stretchability $>500 \%$ was prepared. Extremely fine dispersion as well as a strong secondary network of MWCNTs is the reason behind such high conductivity. This eco-friendly method, apart from the reduction in mixing cycle, exhibits an easy technique to fabricate high performance elastomeric materials 
which can be tailored to the desired applications without any additional steps in the rubber compounding process.

We note that such systems are of basic interest also from another point of view. Obviously, the ionic liquid assisted route of preparation of novel MWCNT-elastomers leads to the formation of highly stretchable and rubber reinforcing granular networks. Recently, Ahir et al. [40] have demonstrated via stress relaxation experiments that pure MWCNT mats have an effective modulus that is temperature invariant, but have a strong (viscoelastic) time-dependence. Such a non-thermal system is most similar to a transient network of elastic rods, or a 'sticky' granular network. Note, this is not the case for single-wall tubes which displayed entropic behaviour akin to a pure polymer network. Furthermore, Ahir et al. [41] showed that exposure of the MWCNT network to near-IR light causes a fully reversible photomechanical expansion, almost four decades larger than would be expected through simple lattice thermal expansion/contraction arguments. Having these points in mind, we may argue that our MWCNT/CR composite is the first hyperelastic 'double network' consisting of an entropic permanently crosslinked rubber network reinforced by a transient wire-like non-thermal network. 


\section{Acknowledgements}

Dr. Petra Pötschke and Dr. Klaus Werner Stöckelhuber are gratefully acknowledged for their beneficial contributions. Dr. Dieter Fischer, Ms. Uta Reuter and Mr. Holger Scheibner are thanked for Raman spectroscopy, TEM and mechanical measurements respectively. Mr. Rene Jurk and Mr. Gaurav Kasaliwal are acknowledged for the help rendered during strain sweep and conductivity measurements respectively. Kalaivani Subramaniam is grateful to Mr. Karthick Selvaraj for his valuable suggestions and support. 


\section{References}

[1] Ebbesen TW. Carbon Nanotubes. Annu. Rev. Mater. Sci. 1994; 24: 235-64.

[2] Treacy MMJ, Ebbesen TW, Gibson JM. Exceptionally high Young's modulus for individual carbon nanotubes. Nature 1996; 381: 678-680.

[3] Ajayan PM. Nanotubes from carbon. Chem. Rev. 1999; 99(7): 1787-1800.

[4] Ajayan PM, Tour JM. Nanotube composites. Nature 2007; 447: 1066-68.

[5] Moniruzzaman M, Winey KI. Polymer nanocomposites containing carbon nanotubes Macromolecules 2006; 39(16): 5194-5205.

[6] Tang W, Santare MH, Advani SG. Melt processing and mechanical property characterization of multiwalled carbon nanotube/high density polyethylene composite films. Carbon 2003; 41(14): 2779-85.

[7] Pötschke P, Fornes TD, Paul DR. Rheological behaviour of multiwalled carbon nanotube / polycarbonate composites. Polymer 2002; 43(11): 3247-55.

[8] Bokobza L. Multiwall carbon nanotube elastomeric composites. Polymer 2007; 48(17): 4907-20.

[9] Das A, Stöckelhuber KW, Jurk R, Saphiannikova M, Fritzsche J, Lorenz H, et al. Modified and unmodified multiwalled carbon nanotubes in high performance solution styrene butadiene and butadiene rubber blends. Polymer 2008; 49(24):5276-83.

[10] Lorenz H, Fritzsche J, Das A, Stöckelhuber KW, Jurk R, Heinrich G, et.al. Advanced elastomer nanocomposites based on CNT-hybrid filler systems. Compos Sci Technol 2009; 69(13): 2135-43.

[11] Das A, Stöckelhuber KW, Jurk R, Fritzsche J, Klüppel M, Heinrich G. Coupling activity of ionic liquids between diene elastomers and multi-walled carbon nanotubes. Carbon 2009; 47(14):3313-21. 
[12] Endo M, Noguchi T, Ito M, Takeuchi K, Hayashi T, Kim YA, et.al. Extreme-

Performance Rubber Nanocomposites for probing and excavating deep oil resources using multi-walled carbon nanotubes. Adv. Funct. Mater. 2008; 18(21):3403-09.

[13] Sun YP, Fu K, Lin Y, Huang W. Functionalised carbon nanotubes: properties and applications. Acc. Chem. Res. 2002; 35(12):1096-1104.

[14] Liang F, Sadana AK, Peera A, Chattopadhyay J, Gu Z, Hauge RH, Billups WE. A Convenient Route to Functionalized Carbon Nanotubes. Nanoletters 2004; 4(7):125760.

[15] Cheng Maa P, Siddiqui NA, Marom G, Kim JK. Dispersion and functionalization of carbon nanotubes for polymer-based nanocomposites: A review. Composites Part A 2010; 41(10): 1345-67.

[16] Jiang MJ, Dang ZM, Xu HP. Significant temperature and pressure sensitivities of electrical properties in chemically modified multiwall carbon nanotube/methylvinyl silicone rubber nanocomposites. Appl. Phys. Lett. 2006; 89(18): 182902-1-182902-3. [17] Rogers RD and Seddon KR. Ionic liquids - solvents of the future. Science 2003; 302(5646): 792-793.

[18] Fukushima T, Aida T. Ionic Liquids for soft functional materials with carbon nanotubes. Chem. Eur. J. 2007; 13(18): 5048-58.

[19] Sekitani T, Noguchi Y, Hata K, Fukushima T, Aida T, Someya T. A rubberlike stretchable active matrix using elastic conductors. Science 2008; 321(5895): 1468-72. [20] Shankar R, Ghosh TK and Spontak RJ. Dielectric elastomers as next-generation polymeric actuators. Soft Matter 2007; 3: 1116-29.

[21] Frackowiak E. Carbon materials for super capacitor application. Phys. Chem. Chem. Phys. 2007; 9: 1774-85. 
[22] Zhang HB, Lin GD, Zhou ZH, Dong X, Chen T. Raman spectra of MWCNTs and MWCNT-based $\mathrm{H}_{2}$-adsorbing system. Carbon 2002; 40(13): 2429-36.

[23] Dresselhaus MS, Dresselhaus G, Saito R, Jorio A. Raman spectroscopy of carbon nanotubes. Physics Reports 2005; 409(2): 47-99.

[24] Fukushima T, Kosaka A, Ishimura Y, Yamamoto T, Takigawa T, Ishii N, et.al., Molecular ordering of organic molten salts triggered by single walled carbon nanotubes. Science 2003; 300(5628): 2072-74.

[25] Wang J, Chu H, Li Y. Why single-walled carbon nanotubes can be dispersed in imidazolium based ionic liquids. ACS Nano 2008; 2(12): 2540-46.

[26] Spitalsky Z, Tasis D, Papagelis K, Galiotis C. Carbon nanotube-polymer composites: chemistry, processing, mechanical and electrical properties. Prog. Polym. Sci. 2010; 35(3): 357-401.

[27] Bhattacharyya S, Sinturel C, Bahloul O, Saboungi ML, Thomas S, Salvetat JP. Improving reinforcement of natural rubber by networking of activated carbon nanotubes. Carbon 2008; 46(7): 1037-45.

[28] Heinrich G, Klüppel M. Recent advances in the theory of filler networking in elastomers. Adv. Polym. Sci. 2002; 160: 1-44.

[29] Payne AR. Effect of dispersion on the dynamic properties of filler-loaded rubbers. J. Appl. Polym. Sci. 1965; 9(6): 2273-84..

[30] Fröhlich J, Niedermeier W, Luginsland HD. The effect of filler-filler and fillerelastomer interaction on rubber reinforcement. Composites Part A 2005; 36(4): 449460.

[31] Jancar J, Douglas JF, Starr FW, Kumar SK, Cassagnau P, Lesser AJ, Sternstein SS, Buehler MJ. Current issues in research on structure-property relationships in polymer 
nanocomposites. Polymer 2010; 51(15): 3321-43.

[32] Robertson CG, Lin CJ, Rackaitis M, Roland CM. Influence of particle size and polymer-filler coupling on viscoelastic glass transition of particle-reinforced polymers. Macromolecules 2008; 41(7): 2727-31.

[33] Akay M. Aspects of dynamic mechanical analysis in polymeric composites. Compos Sci Technol 1993; 47(4): 419-23.

[34] Tsagaropoulos G, Eisenberg A. Direct observation of two glass transitions in silicafilled polymers. Implications to the morphology of random ionomers. Macromolecules 1995; 28(1): 396-98.

[35] Yamamuro O, Minamimoto Y, Inamura Y, Hayashi S, Hamaguchi H. Heat capacity and glass transition of an ionic liquid 1-butyl-3-methylimidazolium chloride. Chem.Phy.Lett. 2006; 423: 371-75.

[36] Mooney MJ. A Theory of large elastic deformation. J.Appl. Phys. 1940; 11(9): $582-92$.

[37] Rivlin RS. Large elastic deformations of isotropic materials. I. Fundamental concepts. Philos. Trans. Roy. Soc. A, 1948; 240 (822): 459-90.

[38] Heinrich G, Vilgis TA. Contribution of entanglements to the mechanical properties of carbon black-filled polymer networks. Macromolecules 1993; 26(5): 1109-1119. [39] Guth E. Theory of Filler Reinforcement. J.Appl. Phys. 1945; 16(1): 20-25.

[40] Ahir SV, Terentev EM, Lu SX, Panchapakesan B. Thermal fluctuations, stress relaxation, and actuation in carbon nanotube networks. Phys. Rev. B 2007; 76:16543742.

[41] Ahir SV, Squires AM, Tajbakhsh AR, Terentjev EM. Infrared actuation in aligned polymer-nanotube composites. Phys. Rev. B 2006; 73: 085420-31. 


\section{Figure captions}

Figure 1 Illustration of the preparation process

Figure 2 Raman spectra of the pristine and modified MWCNTs upon excitation at $785 \mathrm{~nm}$

Figure 3 (a) Electrical conductivity of gum CR and the composites with BMI modified tubes (b) Influence of BMI on the electrical conductivity of the CR/BMI mixtures.

(c) Influence of BMI on the electrical conductivity of the composites with BMI modified tubes .

Figure 4 TEM micrographs of $\mathrm{CR}$ composites $(\mathrm{a} \& \mathrm{~b}) \mathrm{CT}_{3} \mathrm{BMI}_{0}(\mathrm{c} \& \mathrm{~d}) \mathrm{CT}_{3} \mathrm{BMI}_{1}$, (e\&f) $\mathrm{CT}_{3} \mathrm{BMI}_{5},(\mathrm{~g} \& \mathrm{~h}) \mathrm{CT}_{3} \mathrm{BMI}_{10}$

Figure $5(\mathrm{a} \& b)$ Strain dependence of $\mathrm{E}^{\prime}$ for $\mathrm{CR}$ and the composites measured using Dynamic Mechanical Thermal Analyser at a frequency of $10 \mathrm{~Hz}$.

(c) Schematic illustration of the formation of MWCNT networks in presence of BMI.

Figure 6 (a) Storage modulus ( $\left.E^{\prime}\right)$ and loss modulus (E") vs temperature curves of neat $\mathrm{CR}$ and the composites at $10 \mathrm{~Hz}$ frequency.

(b) Loss tangent ( $\tan \delta$ ) ys temperature curves of neat $\mathrm{CR}$ and the composites at $10 \mathrm{~Hz}$ frequency; Inset: A zoomed plot of the loss tangent curve in the temperature range of 90 to $-50^{\circ} \mathrm{C}$ to point the secondary shoulder.

Figure 7 (a) Tensile stress vs strain plots of neat CR and the composites.

(b) Influence of BMI on the tensile modulus at $300 \%$ elongation.

(c) Mooney-Rivlin plots of $\mathrm{CT}_{0}$ and $\mathrm{CT}_{3} \mathrm{BMI}_{1}$.

\section{Table captions}

Table 1 Chemical Structures 
Table 1

\begin{tabular}{ll}
\hline Material Chemical Structure & Che
\end{tabular}

Polychloroprene Rubber<smiles>CCC(Cl)=CCC(C)CC</smiles>

1-butyl 3-methyl imidazolium bis (trifluoromethylsulphonyl) imide
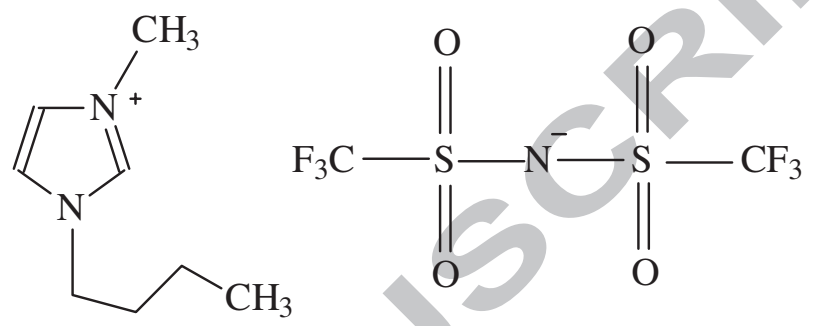


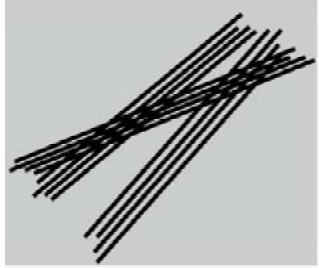

MWCNTs
Ionic Liquid

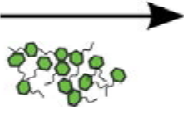

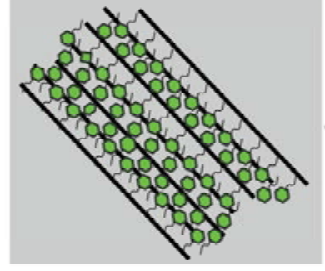

Modified MWCNTs

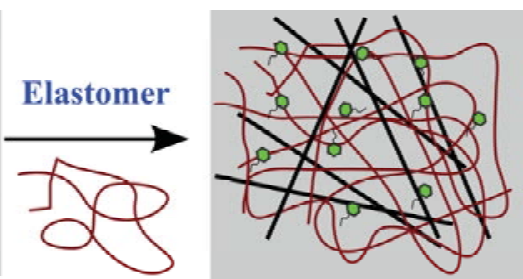

Composites 


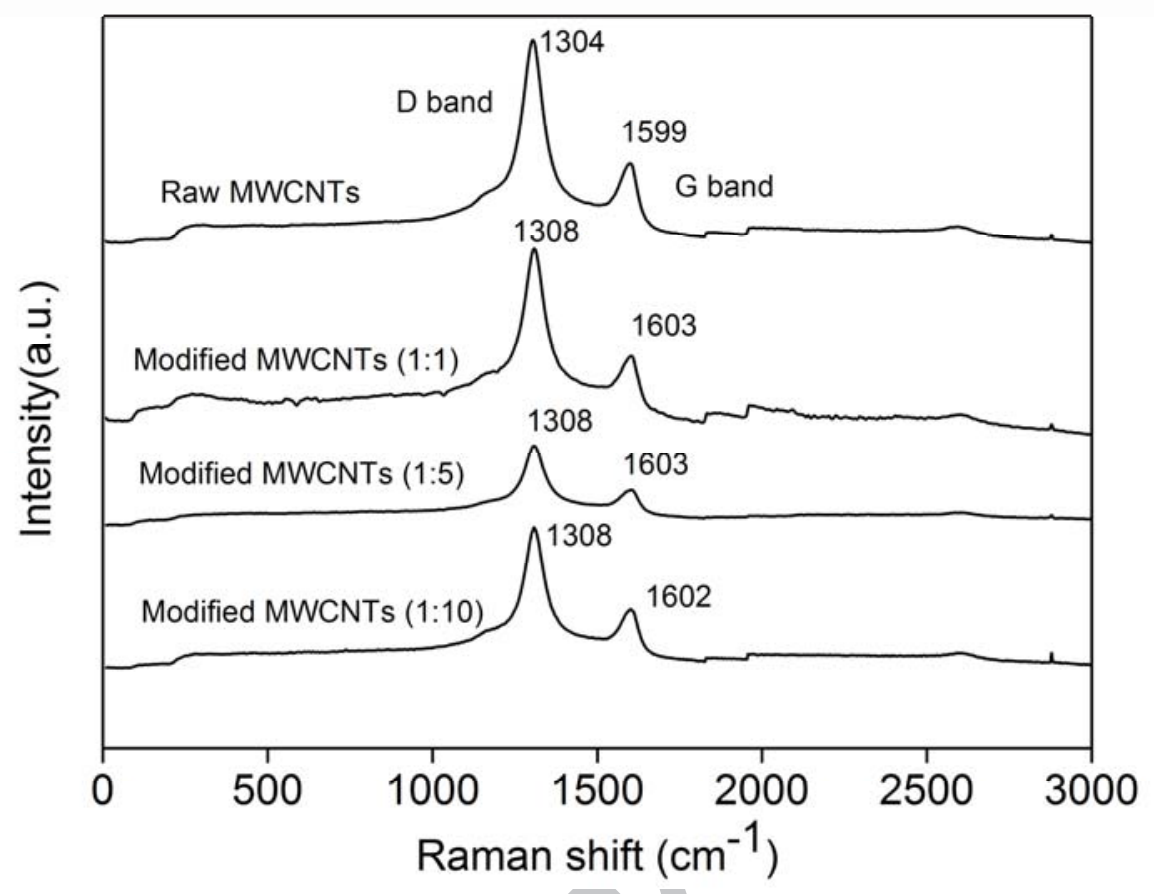




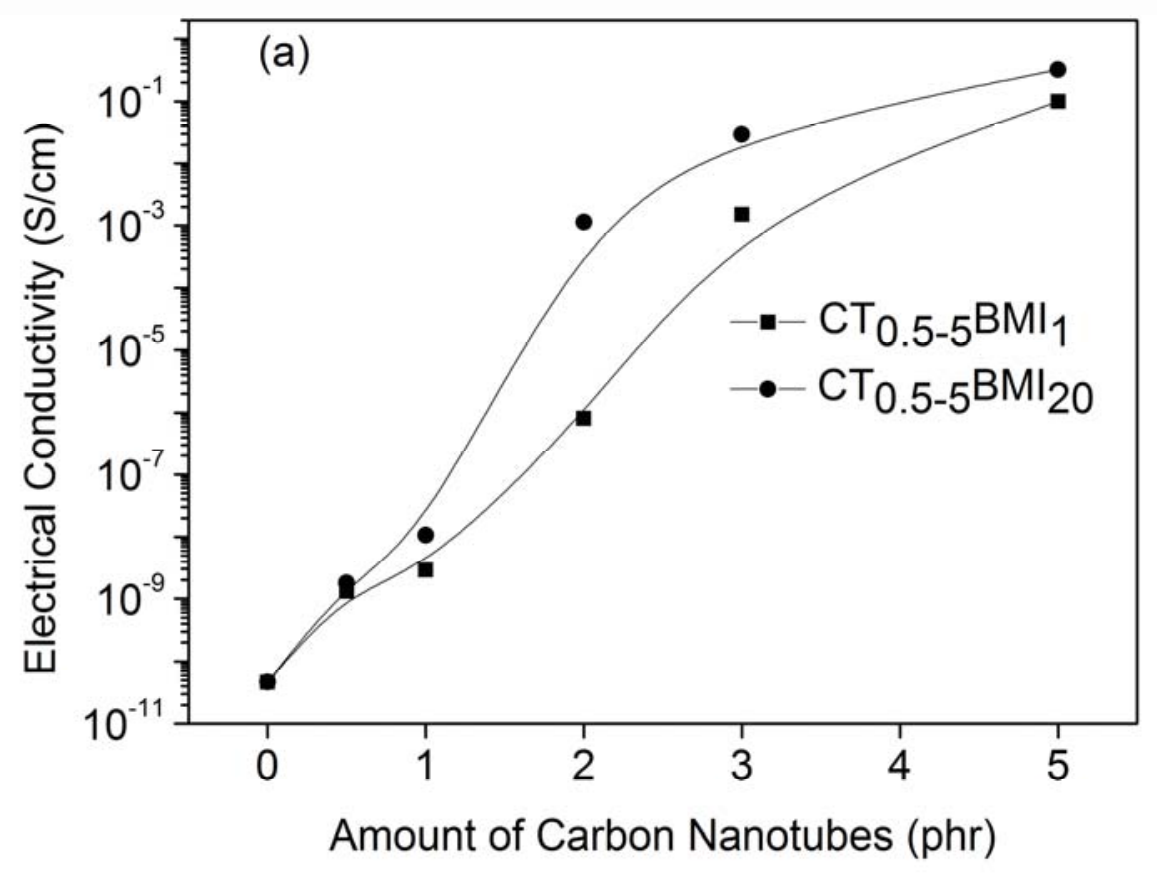




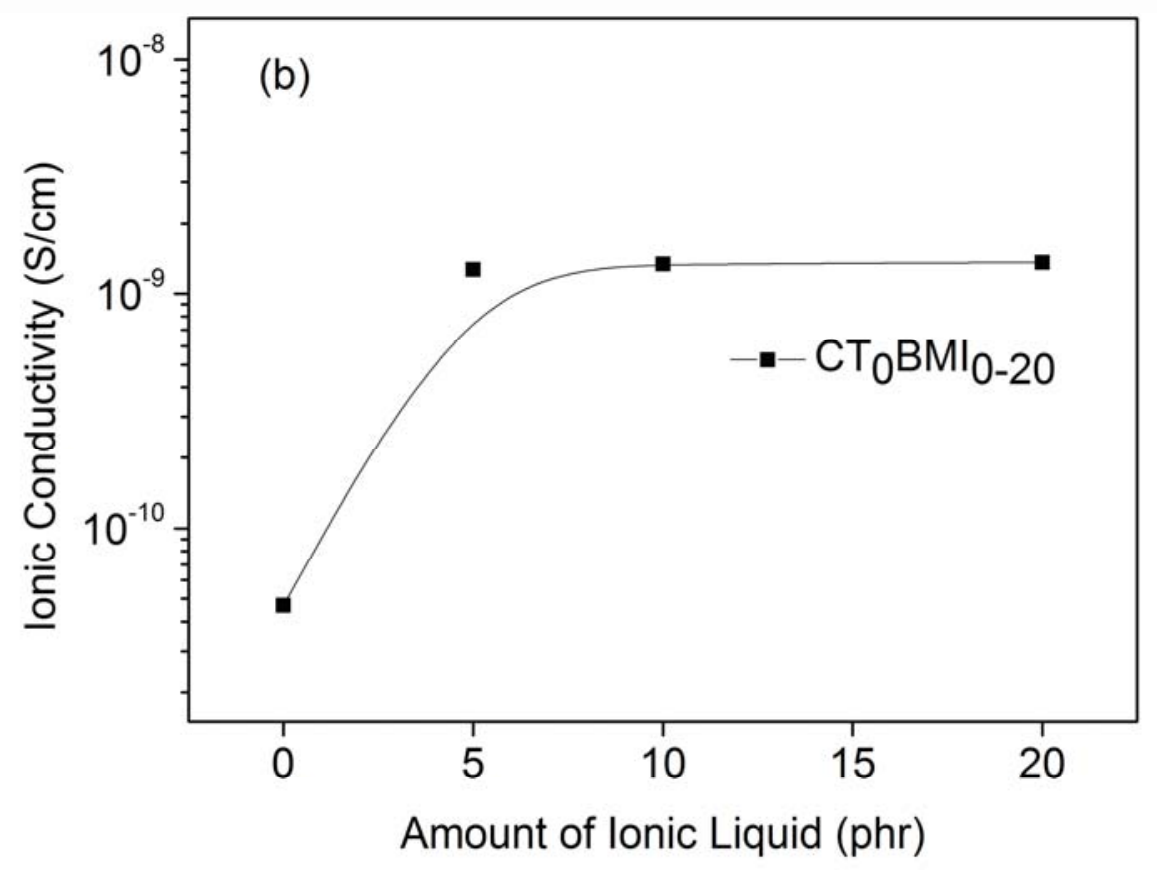




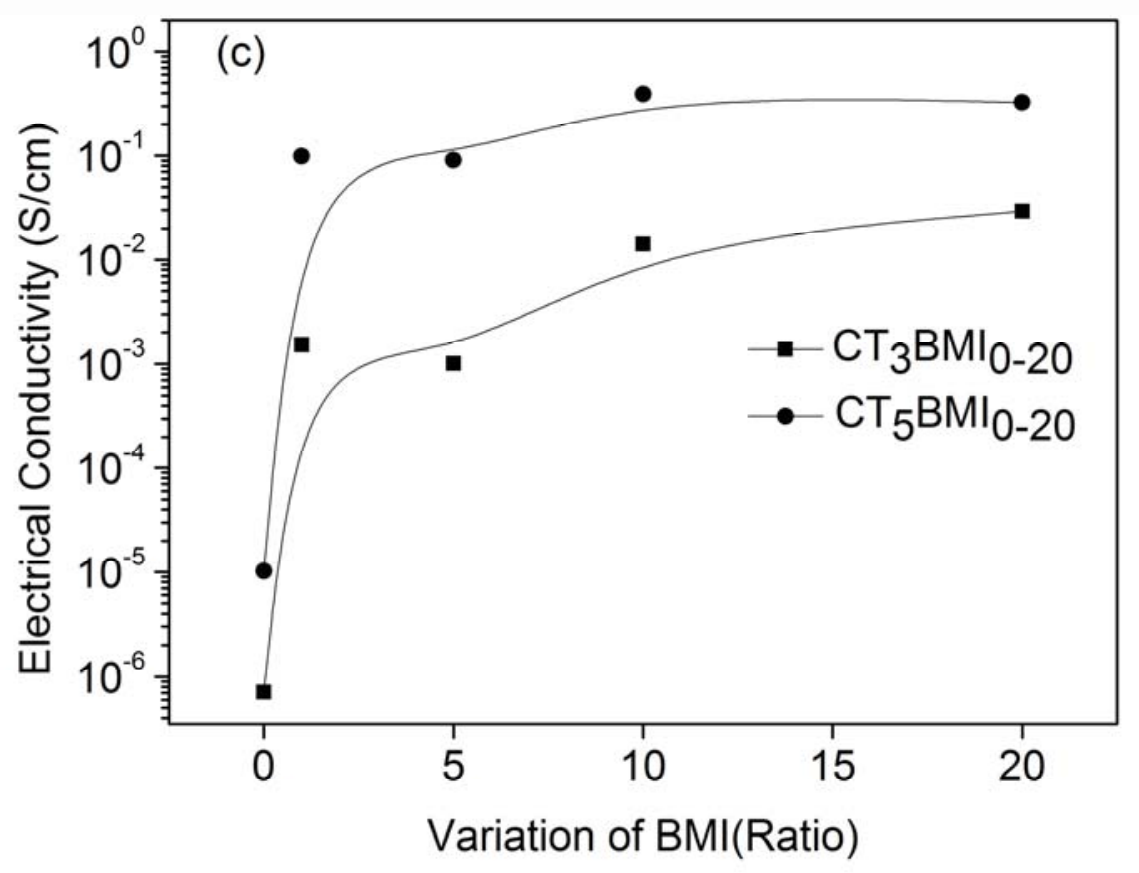




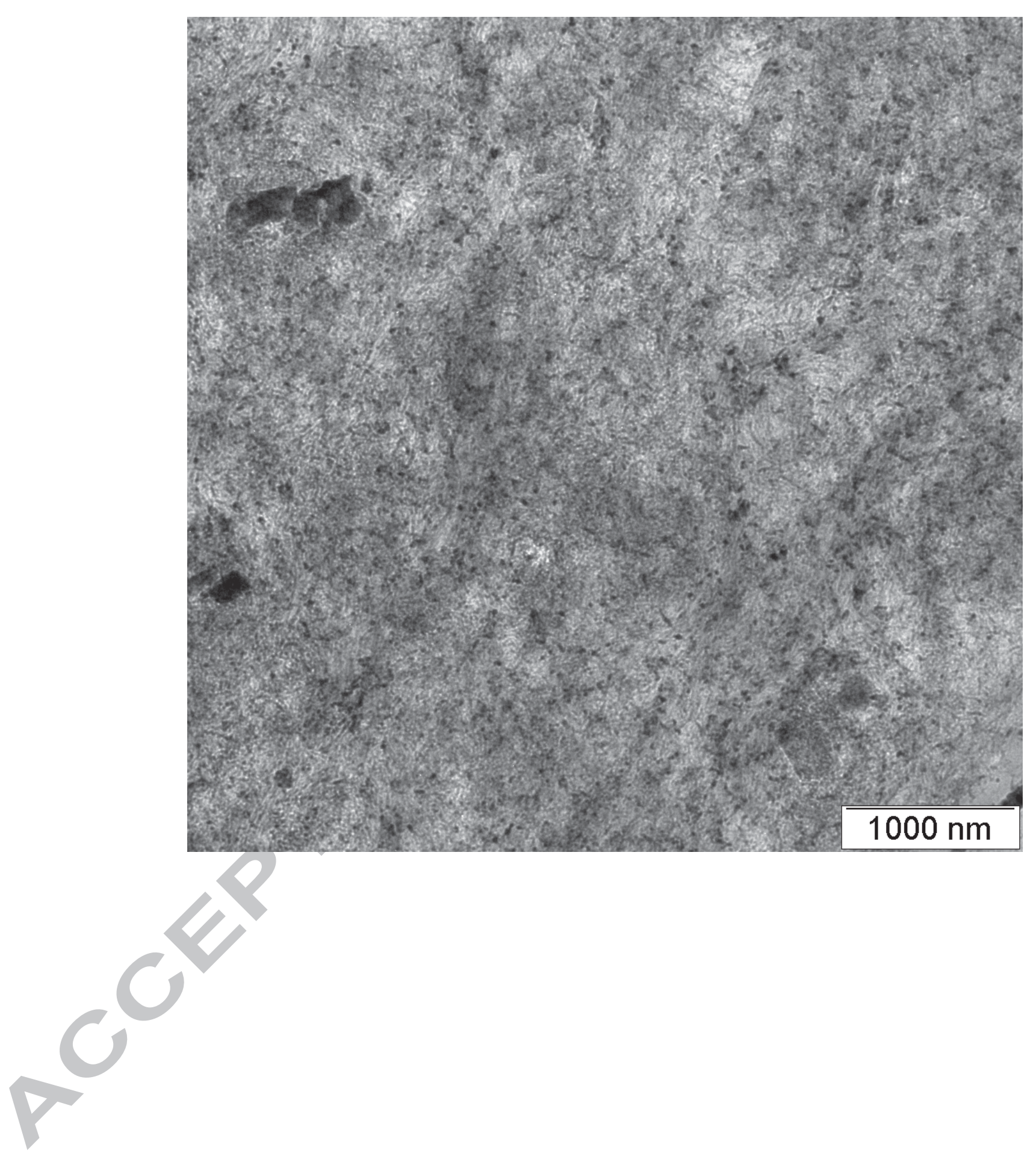



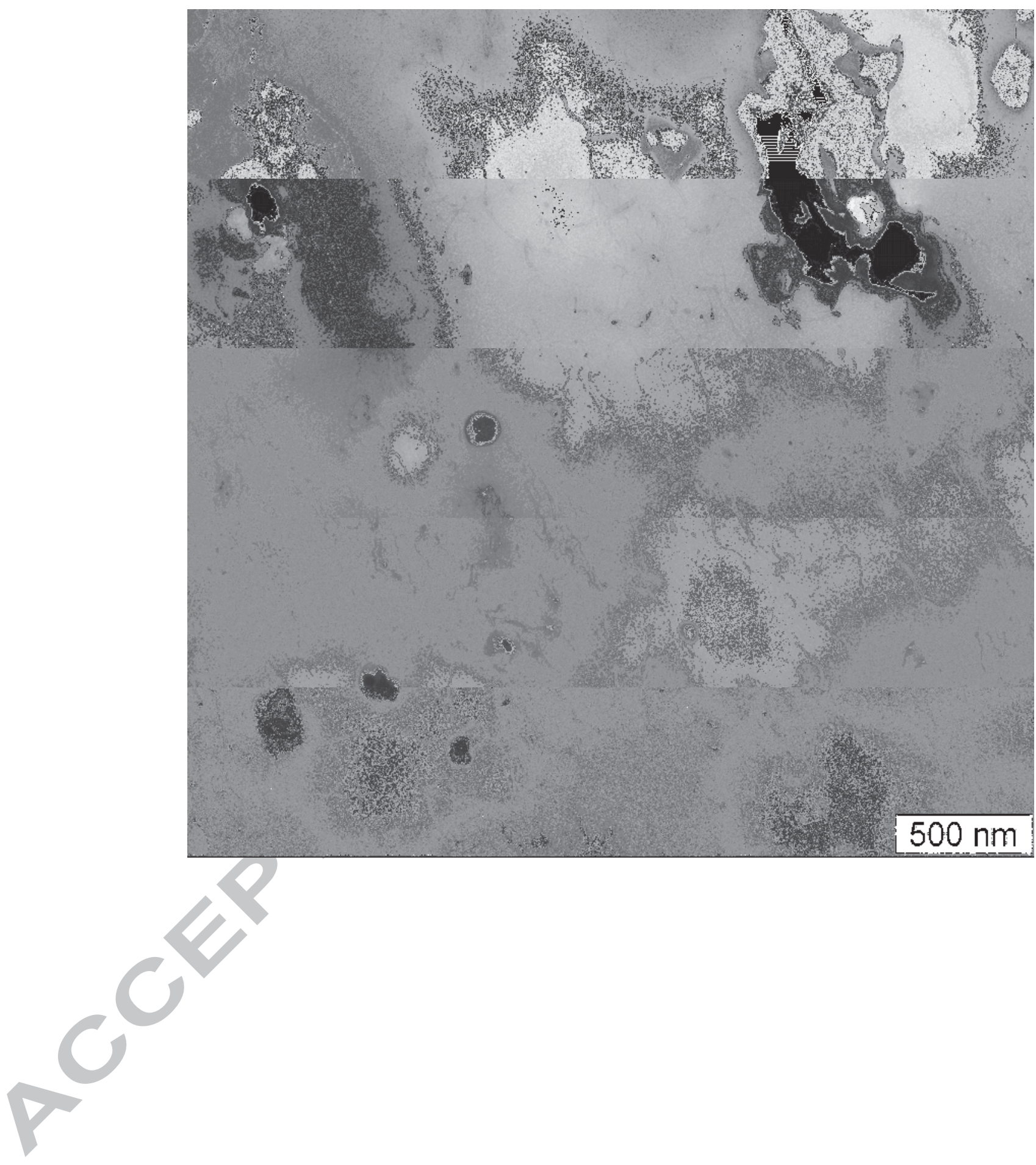


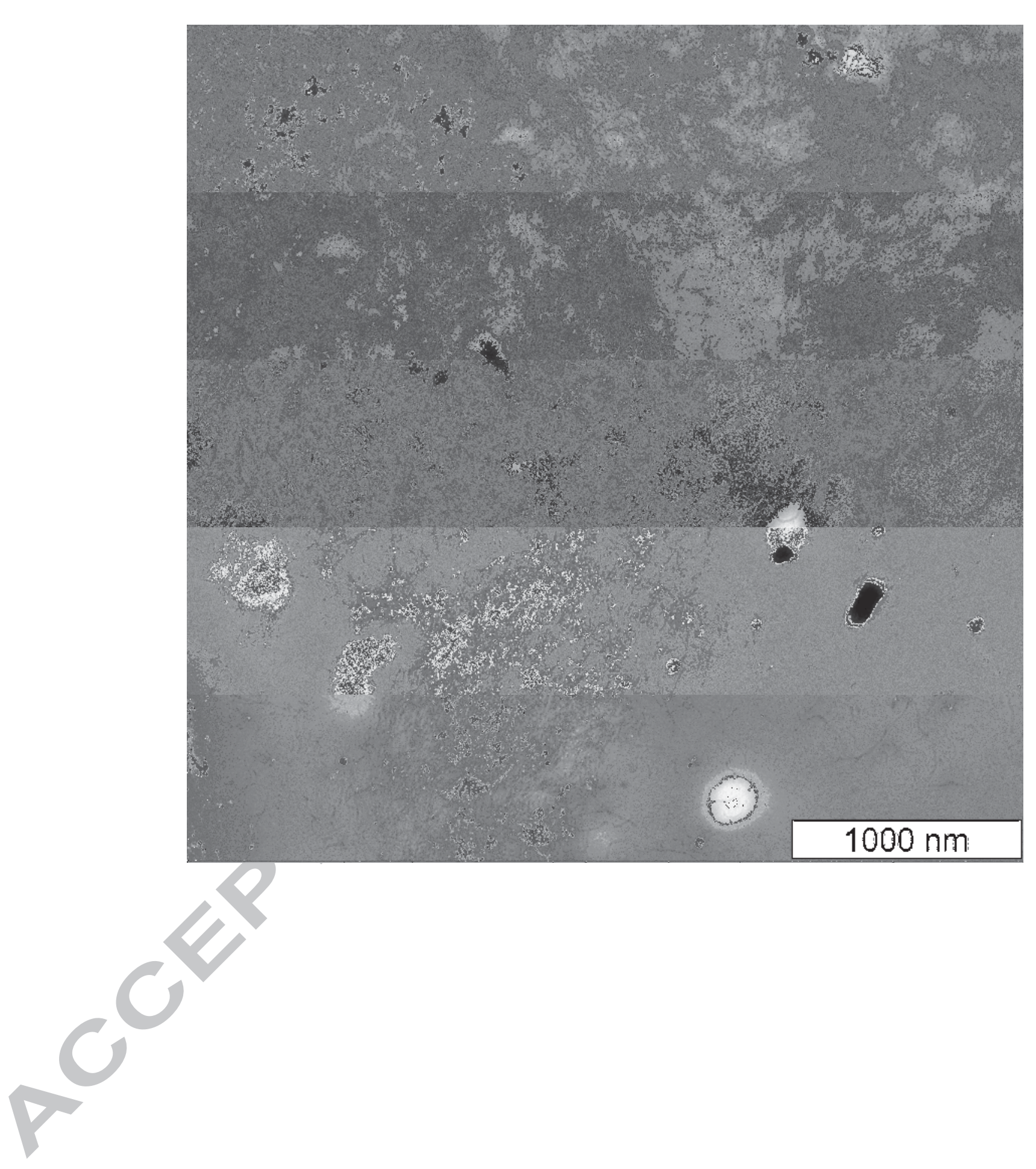




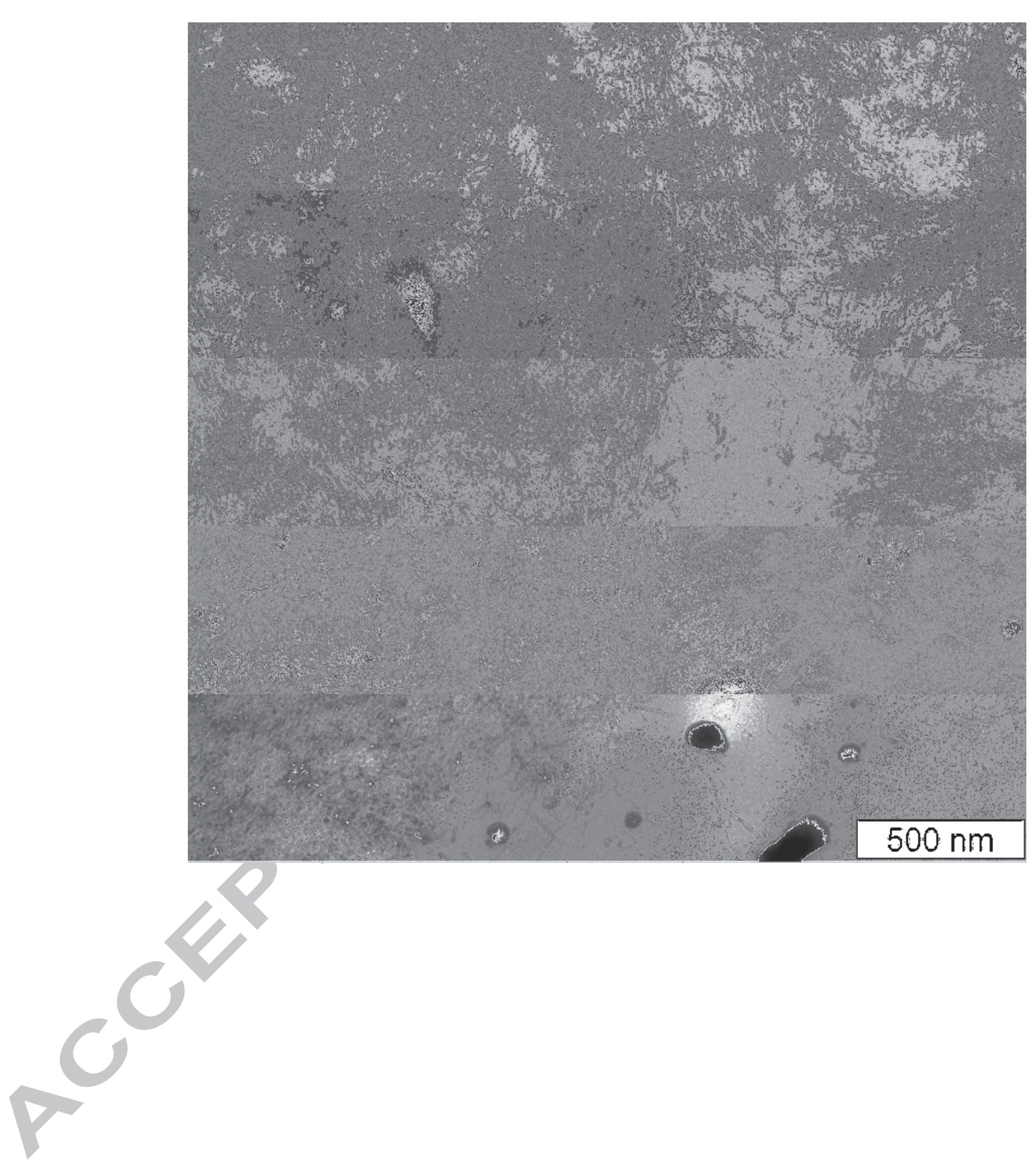




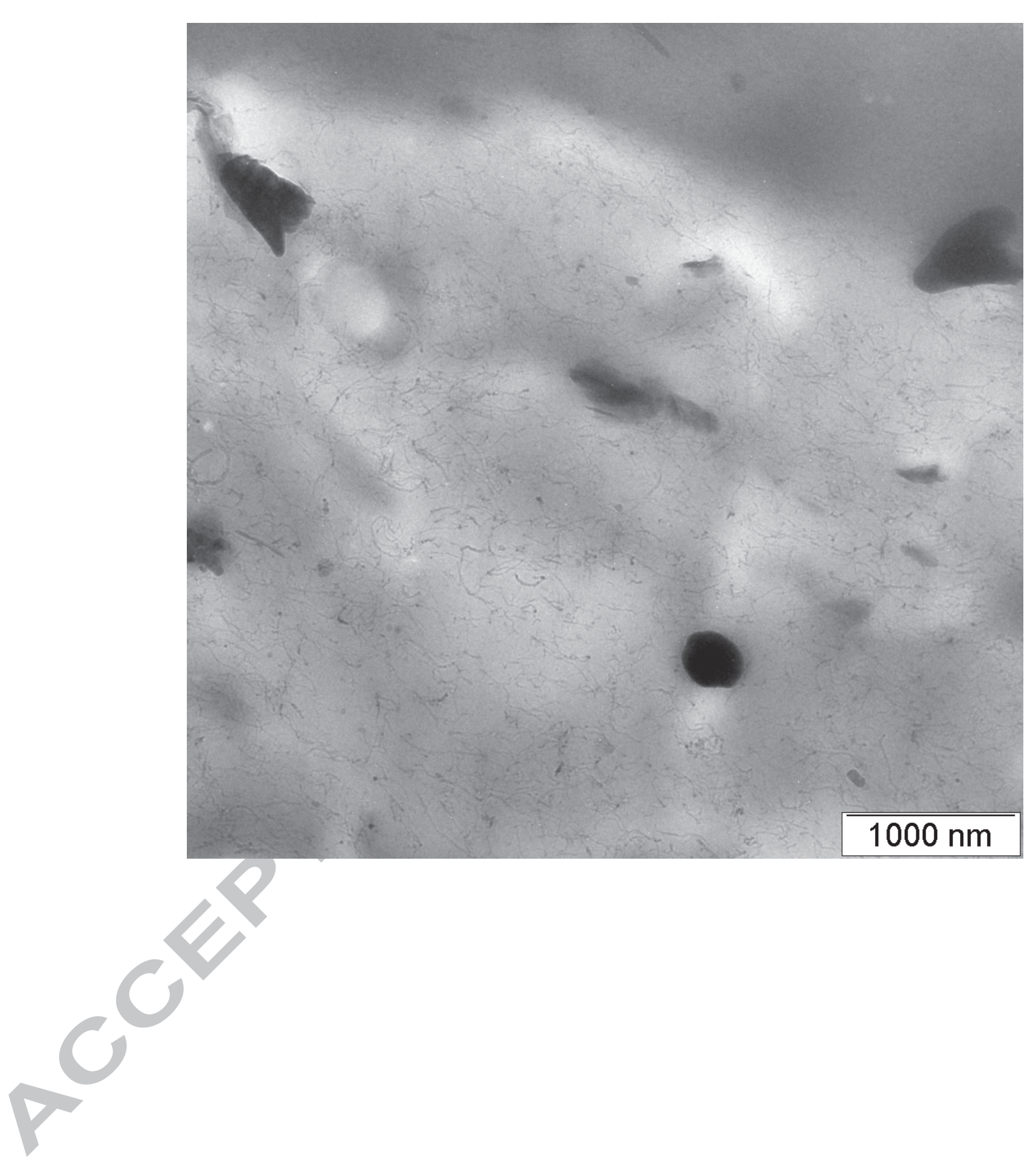




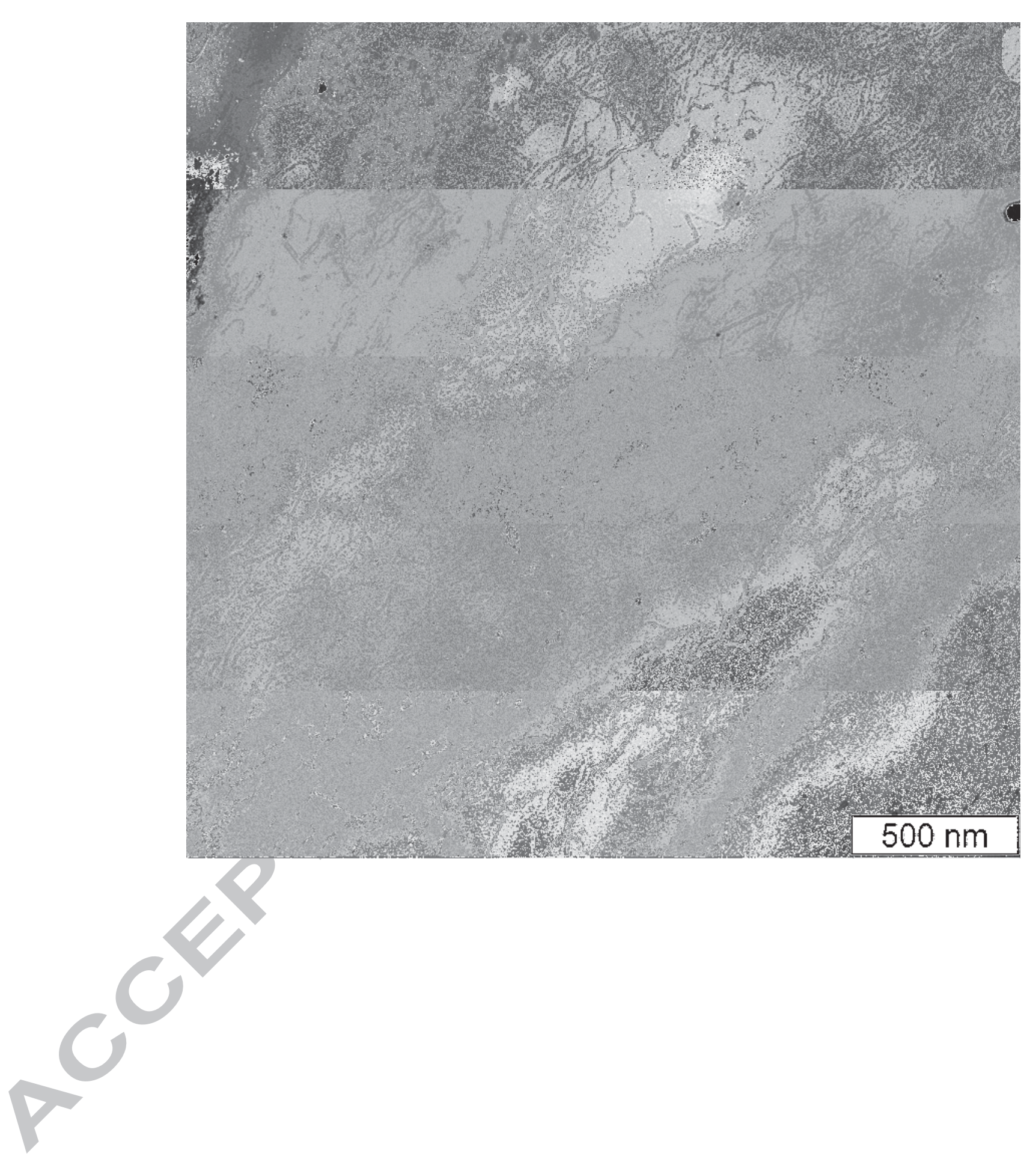




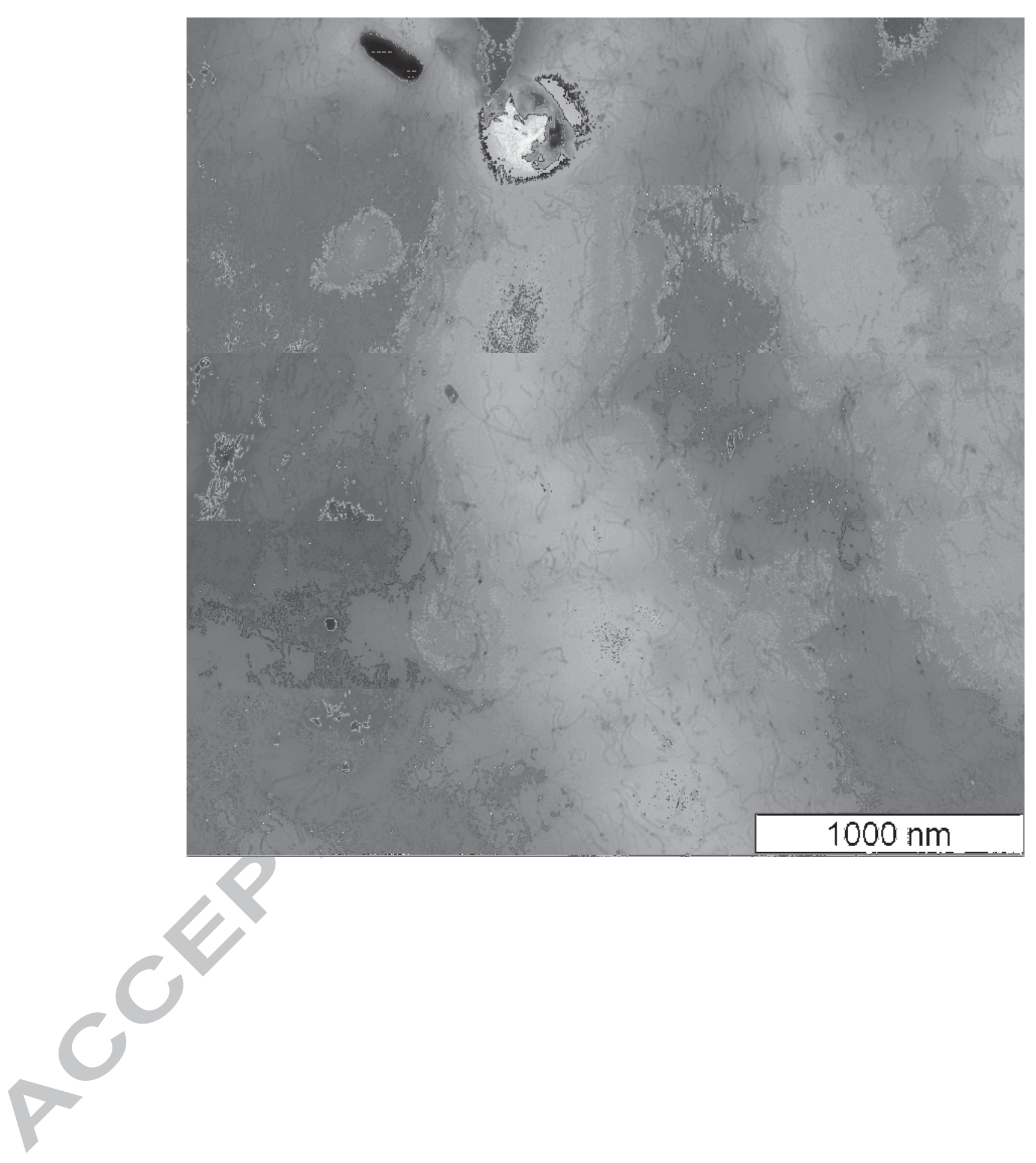




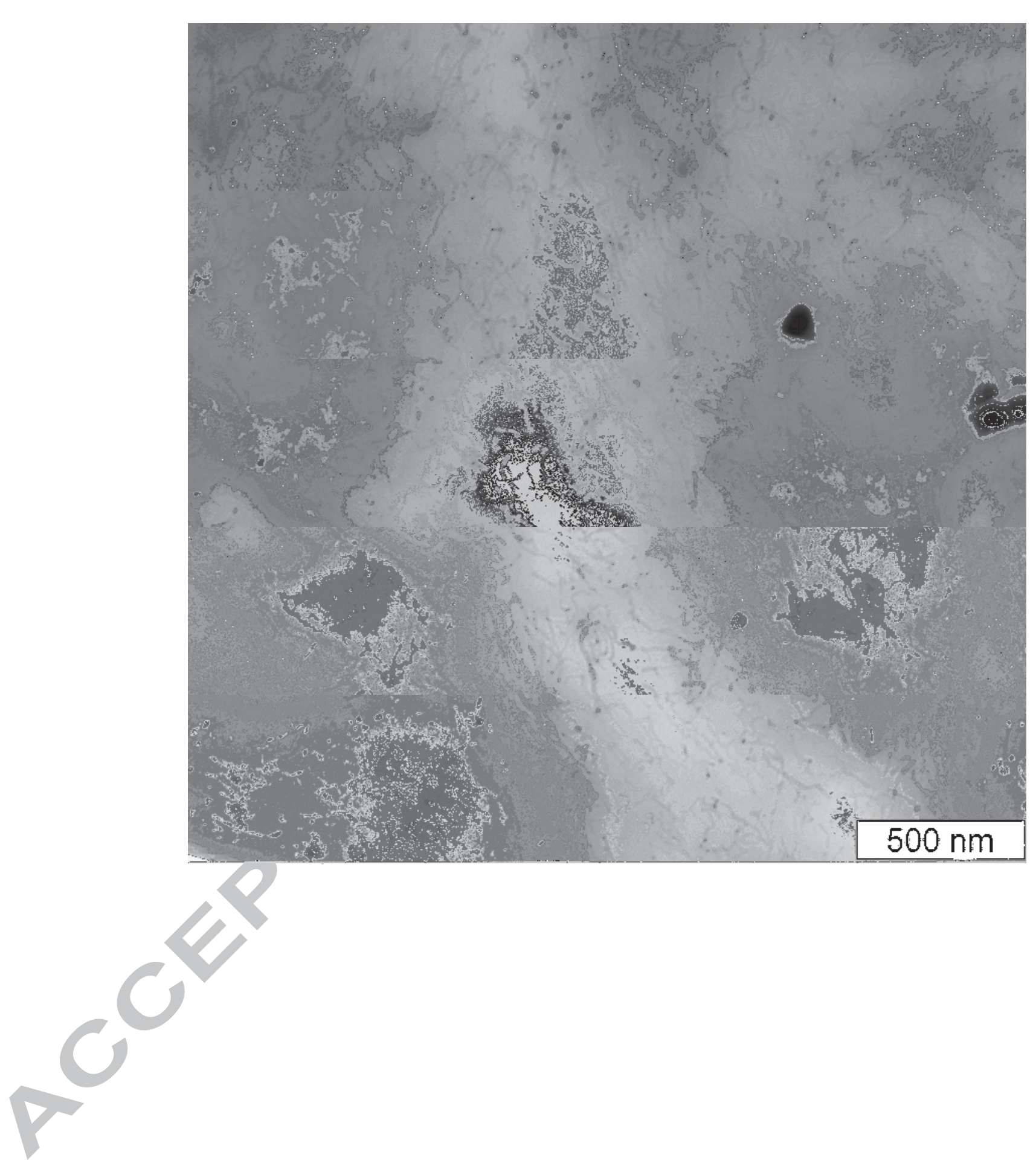




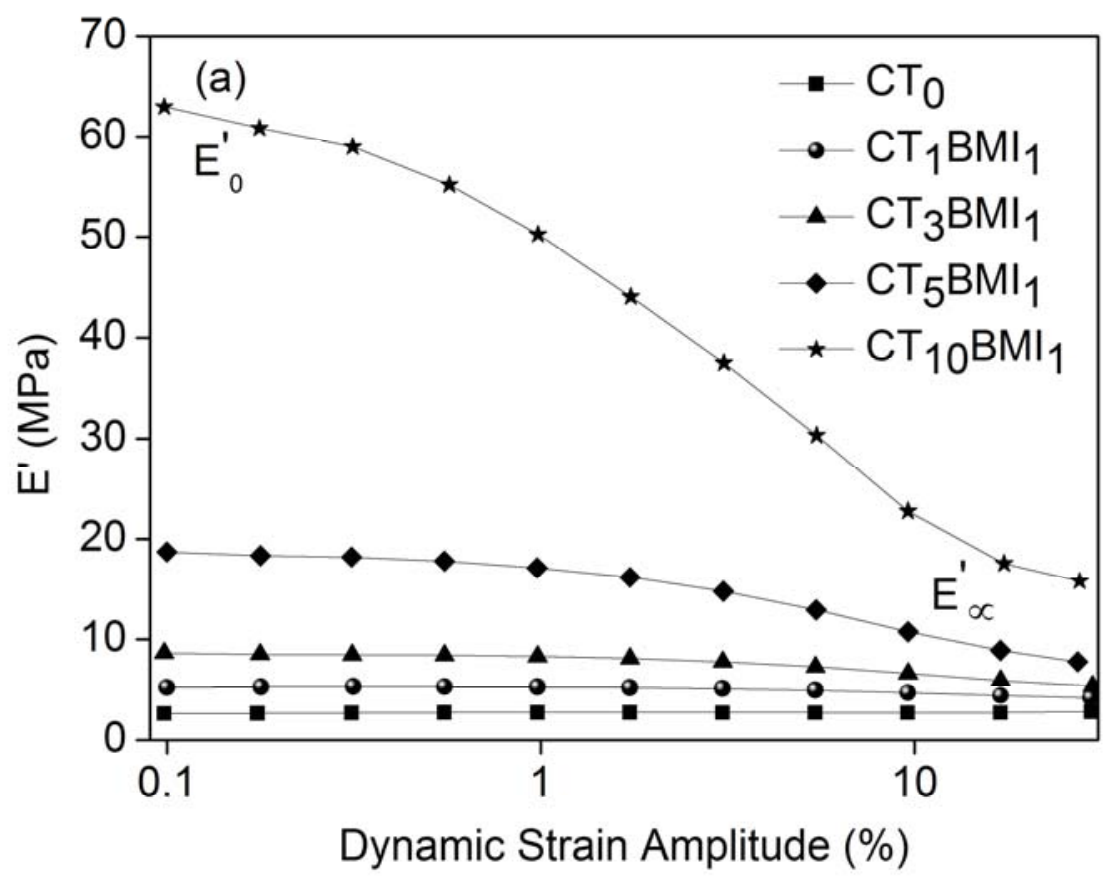




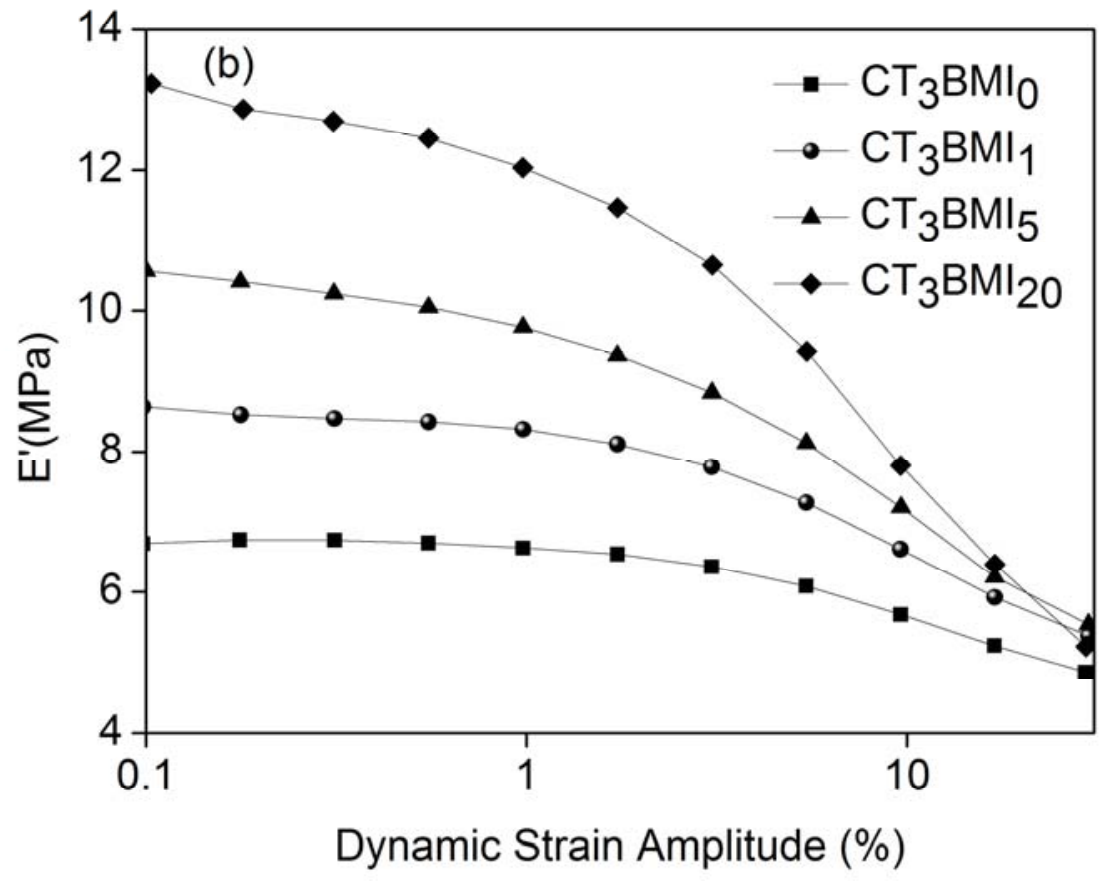




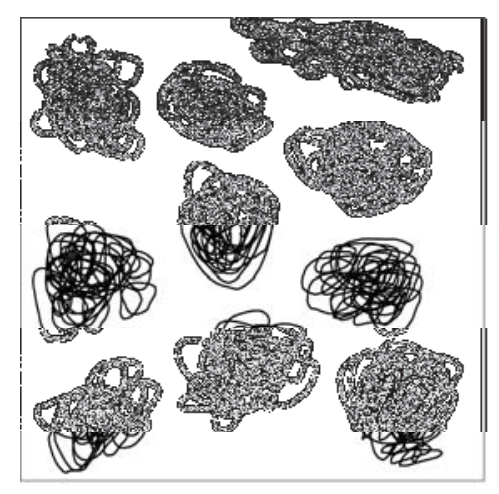

Clusters of MWCNTs

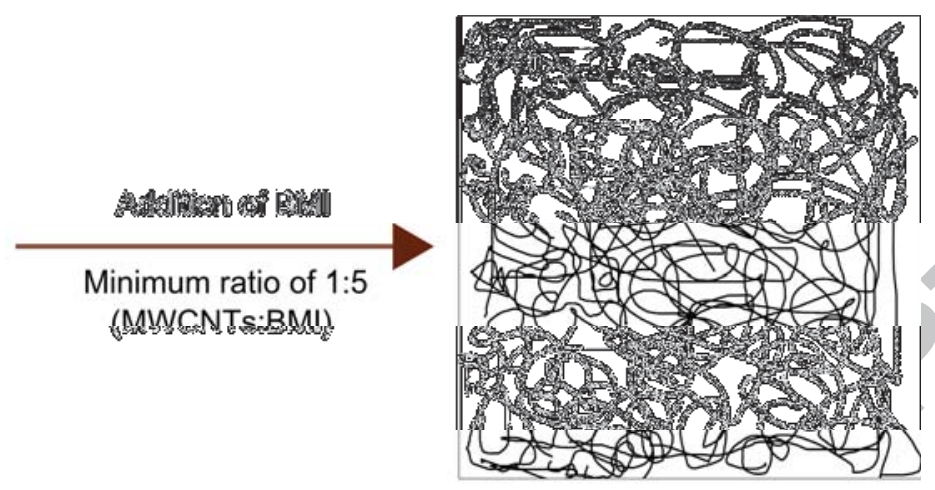

MWCNT networks in CR 


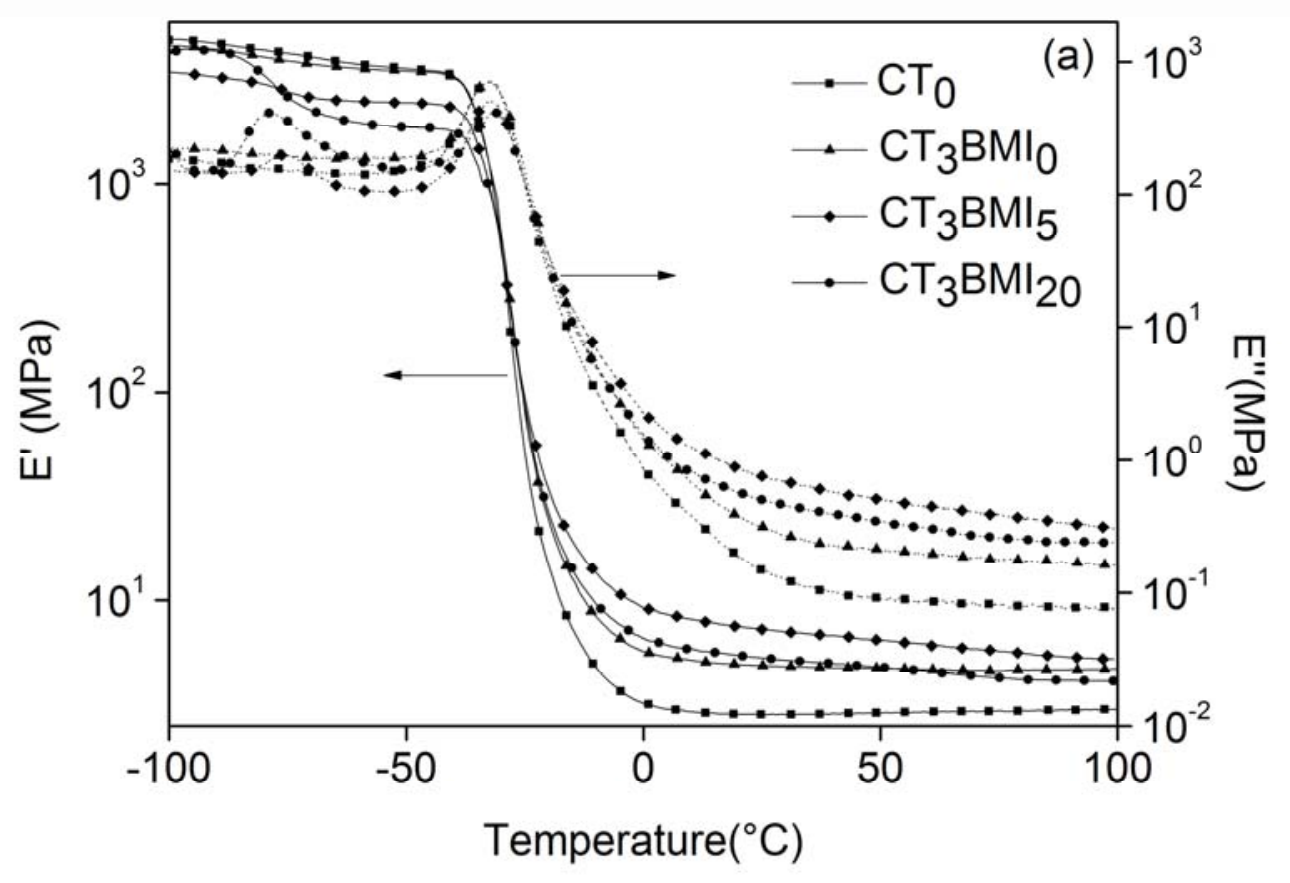




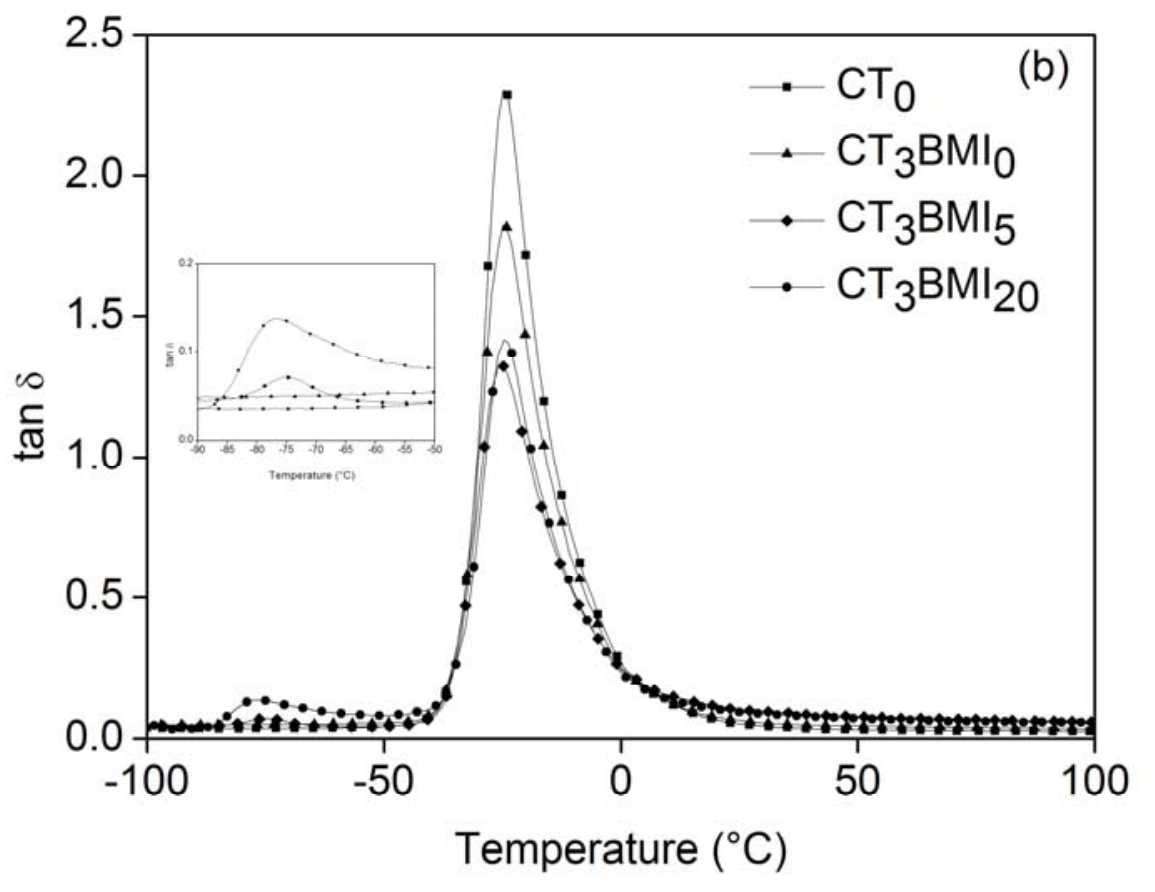




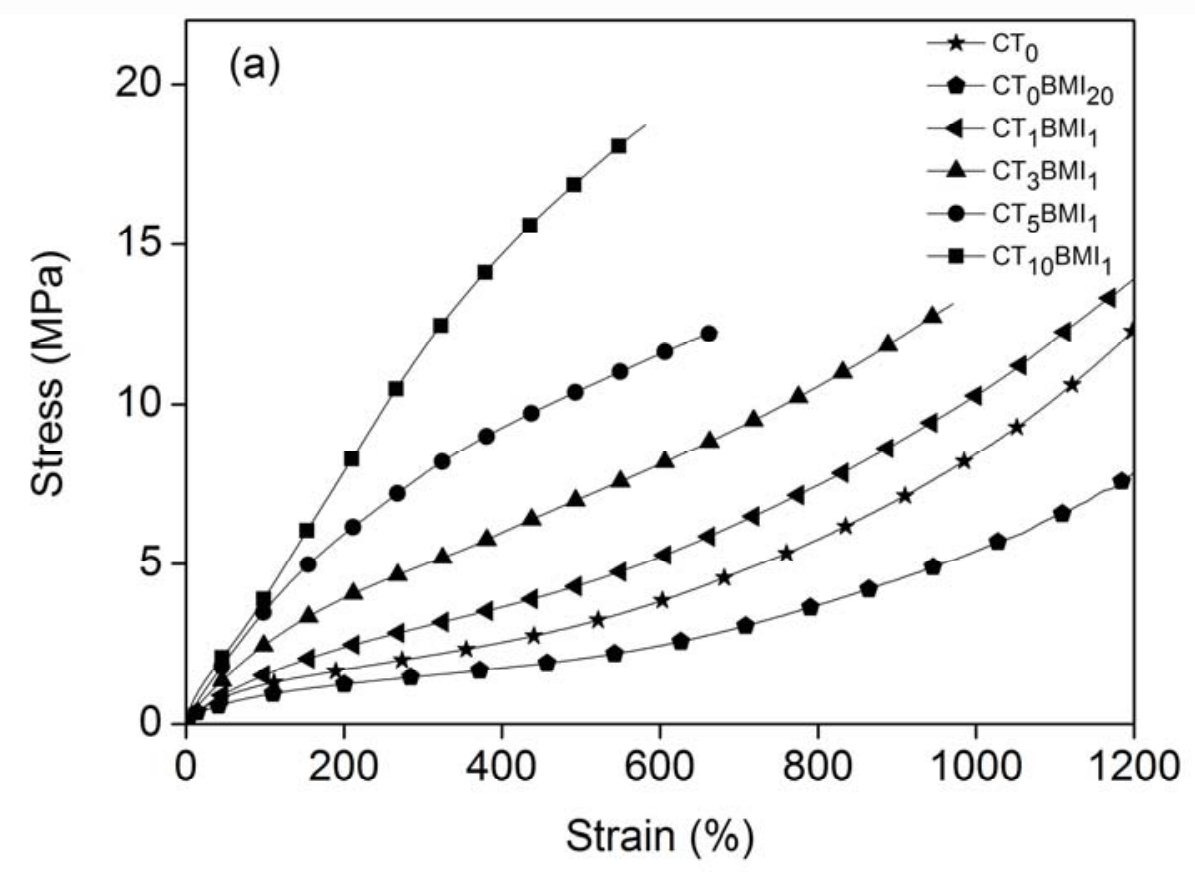




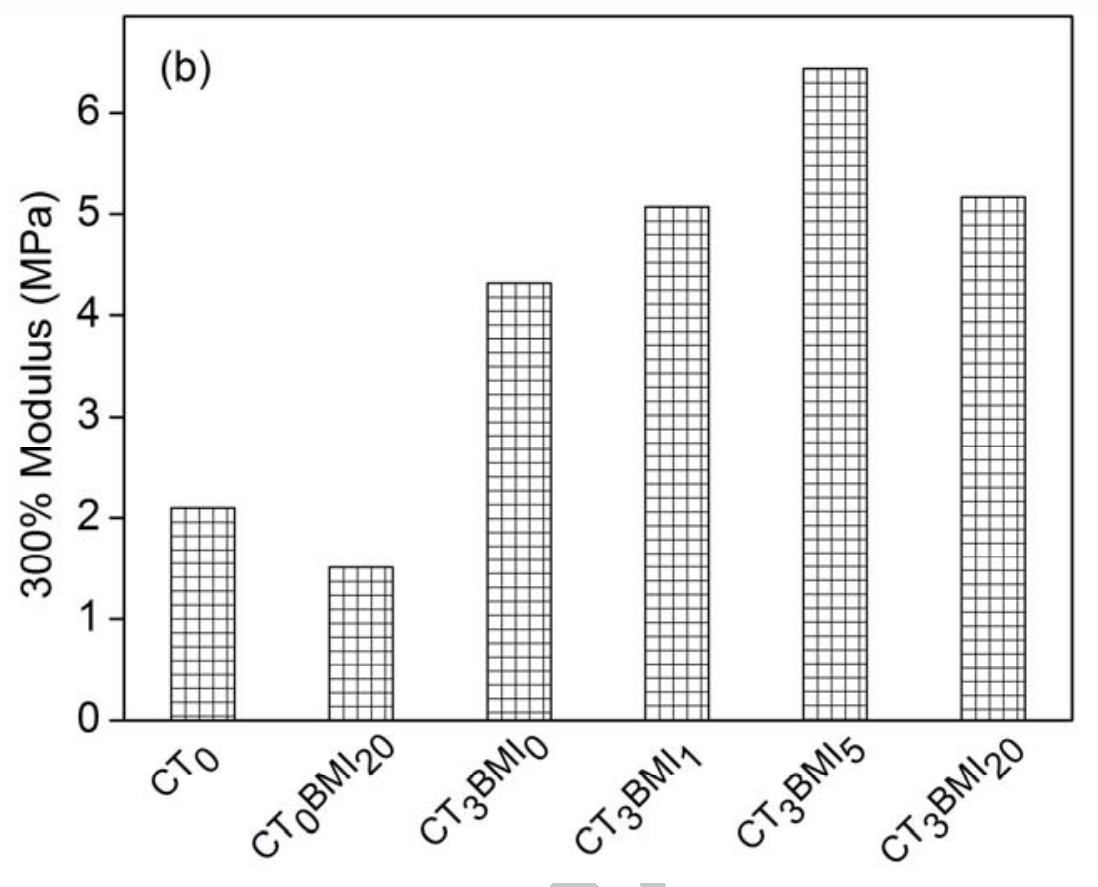




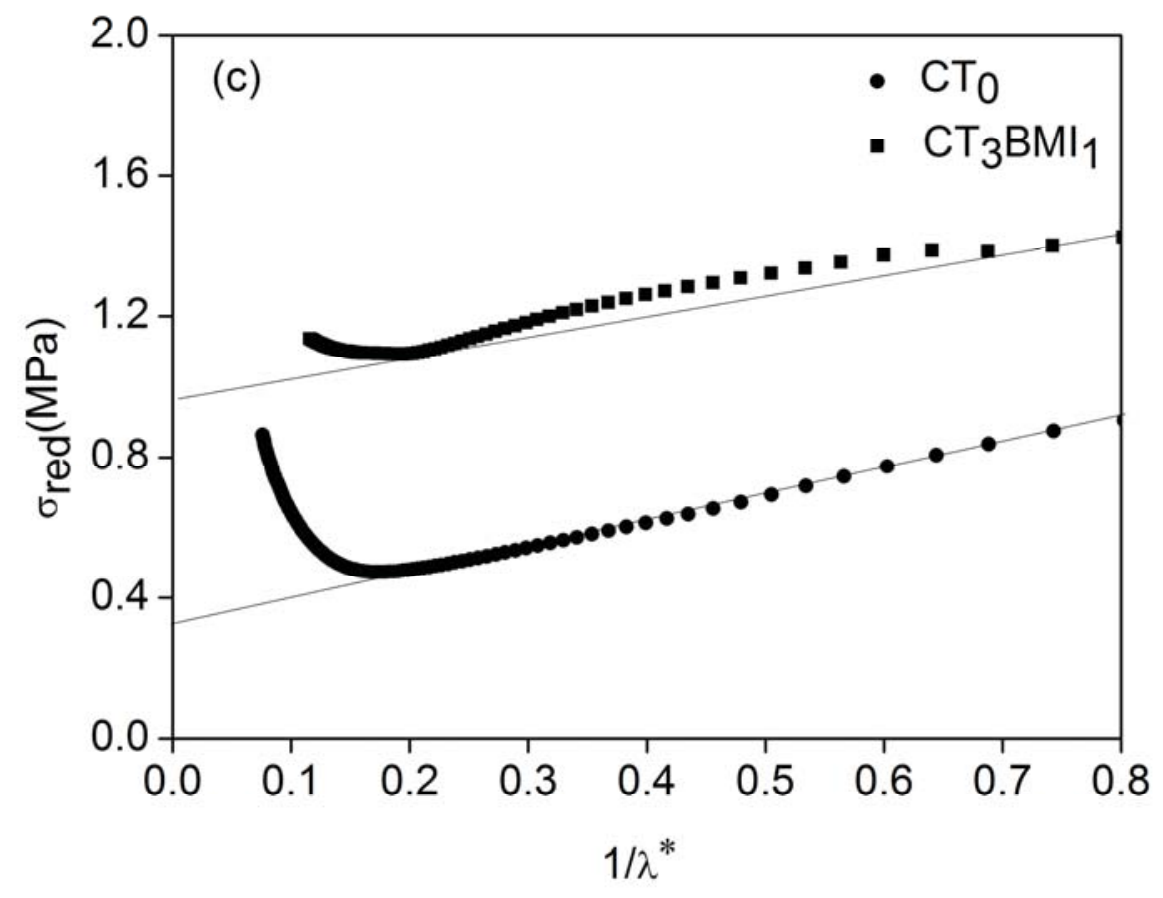

